\title{
Las rentas del Almirantazgo castellano. Entre la ley y la costumbre
}

\author{
The Castilian Admiralty Income: Between Law and Custom
}

\author{
Eduardo AzNAR VALLEJo \\ Universidad de La Laguna \\ eaznar@ull.edu.es
}

\section{RESUMEN}

Análisis de la evolución de las rentas del almirantazgo castellano durante la Baja Edad Media, en especial durante el siglo XV. Estudia el origen y evolución de los ingresos, indicando sus fuentes de obtención y las repercusiones del régimen de arrendamiento sobre los contribuyentes. Presta especial atención a los conflictos jurisdiccionales y a la aplicación de la justicia.

Palabras clave: Almirantes, fiscalidad, guerra naval, puertos, productos vedados, justicia, Castilla (Sevilla, Canarias, Granada), Berbería.

\begin{abstract}
Analysis of the evolution of the Castilian Admiralty income in the late Middle Ages and especially in the fifteenth century. The origin and development of such revenues is studied by identifying their supply sources as well as the repercussions of the leasing system on tax payers. It focuses on jurisdictional conflicts and on the many measures that were taken in the practice of the law.
\end{abstract}

Key words: Admirals, Taxation, Naval Warfare, Harbors, Banned Products, Justice, Castile (Seville, Canary Islands, Granada), Barbary.

Sumario: 1. El valor de las rentas. 2. Las rentas de la guerra marítima. 2.1. La situación inicial. 2.2. El creciente peso de los quintos. 3. El control de los puertos. 3.1. El punto de partida. 3.2. La lenta y total transformación. 3.3. Los aranceles clásicos. 4. La guarda de las "cosas vedadas".

A pesar de su supuesta importancia, la repercusión económica de las rentas almirantazgo es poco conocida. La causa es similar a las que afectan a otros sectores de la actividad marítima del reino castellano: la falta de fuentes contables. Ello obliga a indagar en documentos de carácter institucional (nombramientos, privilegios, conflictos jurisdiccionales) y en informaciones generales, a fin de paliar esta laguna. 
Tales rentas procedían de tres ramos principales: actividades bélicas, fuesen estas oficiales o particulares; control de las operaciones portuarias; y guarda de las "cosas vedadas". A ellas hay que sumar las procedentes de la acción jurisdiccional sobre otras cuestiones acaecidas en mares y ríos, en las que no entraremos. Conviene advertir que el almirantazgo fue concebido para actuar en el conjunto del reino, aunque sólo se consolidó en la fachada sur (arzobispado de Sevilla) y con excepciones ${ }^{1}$.

\section{EL VALOR DE LAS RENTAS}

El primer aspecto a considerar es el valor de las rentas. La información sobre este aspecto es pobre y parcial, pues se limita a los arrendamientos de ciertos años, en los que se suele excluir los capítulos más productivos y se incluyen otros no directamente vinculados a las rentas del oficio.

El primer contrato conocido comenzó en febrero de 1427, con vigencia de seis años y un monto de 2.100 doblas baladíes anuales ${ }^{2}$. Su titular fue Luis Fernández de Marmolejo, regidor de Sevilla. Las condiciones suponían el traspaso de las rentas de guardas, barquetas, alcaldías, alguacilazgos escribanías y sacas; con reserva para el almirante de los derechos provenientes de la organización de armadas, el tercio del quinto real, tanto en guerra como fuera de ella, y la saca del pan para dentro y fuera del reino, con la excepción del enviado a los puertos privilegiados de Cartagena, Fuenterrabía y San Sebastián. El siguiente arrendamiento corresponde al periodo comprendido entre marzo de 1434 y diciembre de $1436^{3}$. El arrendatario era el mismo

1 * Este artículo forma parte del proyecto de investigación De mar a mar. Los puertos castellanos en la Baja Edad Media (ref. HAR2010-17693), financiado por el Ministerio de Economía y Competitividad.

${ }^{* *}$ Este trabajo es un homenaje al profesor Miguel Ángel Ladero Quesada en reconocimiento a su magisterio.

La moderna historia del almirantazgo arranca de la obra de F. Pérez EMBID, El almirantazgo de Castilla hasta las capitulaciones de Santa Fe, Sevilla, 1944. Su investigación no fue retomada hasta muchos años después por E. AzNAR VALLEJo, "Navegación atlántica y orígenes del Estado Moderno. El papel del almirantazgo", Navegación marítima del Mediterráneo al Atlántico (ed. A. Malpica), Granada, 2001, pp. 59-95; y J.M. CALDERÓN ORTEGA, El Almirantazgo de Castilla. Historia de una institución conflictiva (1250-1560), Alcalá de Henares, 2003. Un buen estado de la cuestión sobre antiguas y nuevas investigaciones en M. A. LADERo QueSADA, "El almirantazgo de Castilla en la Baja Edad Media. Siglos XIII a XV", La institución del Almirantazgo en España, Madrid, 2003, pp. 57-82.

${ }^{2}$ A(rchivo) G(eneral) I(ndias), Justicia, leg. 1143 A (consultado a través del portal PARES): El contrato, firmado en Toro el 13 de julio de 1426, incorpora un poder de Luis Fernández Marmolejo en favor de Hernán Peraza, fiel ejecutor de Sevilla, primo suyo y futuro señor de Canarias. La vinculación del almirantazgo con los asuntos canarios puede verse en M.A. LADERo QuesADA, "Los señores de Canarias en su contexto sevillano (1403-1477)”, Anuario de Estudios Atlánticos no 23 (1977), pp. 125-164; y en R. SÁnchez SAus, "Nuevos datos y sugerencias acerca del entorno sevillano de las primeras expediciones a Canarias" y "El almirantazgo de Castilla y las primeras expediciones a Canarias", En la España Medieval no 25 (2002) pp. 381-401 y no 28 (2005) pp. 177-195.

${ }^{3}$ A(rchivo) D(ucal) A(lba) 77.29: Traslado del poder otorgado por Luis Fernández de Marmolejo, veinticuatro de Sevilla, el 17 de octubre de 1433 en El Espinar, nombrando como su procurador a Sancho López de Madrigal, su criado, para usar el oficio del almirantazgo en el arzobispado de Sevilla, que él tiene por delegación del almirante D. Fadrique; ADA, 77.28: Traslado de la escritura de obligación hecha el 21 de noviembre de 1433 en Cantillana por Sancho López de Madrigal, alcalde de la armada y 
y el precio a pagar era de 6.233 doblas baladíes, 2 tomines y 8 dineros de plata. Los términos del acuerdo eran prácticamente los mismos, con la única novedad de la reserva para el almirante del quinto de los canarios. A partir de enero de 1437, el tomador fue Diego Álvarez de la Becerra, vecino de Sevilla, que lo recibió por tres años y precio de 6.900 doblas baladíes ${ }^{4}$. En este caso no hubo ningún tipo de innovación.

A fines de 1453 el monarca ordenó a los contadores mayores arrendar la renta del almirantazgo para uno o varios años, con las condiciones con las que Diego López de Sevilla, veinticuatro de la ciudad, la había tenido hasta entonces ${ }^{5}$. La concesión a este databa de 1449 y había sido otorgada por cinco años ${ }^{6}$. La razón aducida era que el almirante se encontraba fuera del reino "con permiso real". Por eso, en la documentación Diego López figura como lugarteniente del almirante ${ }^{7}$. En primer remate se concedió a Ferrand González de Guadalcanal, vecino de Sevilla, por tres años y precio de 2.500 doblas de la banda, "cerradas de marcos y chancillería", en cada uno de ellos. Esta oferta se hizo con ciertas condiciones, que muestran su carácter artificial. En primer lugar, que en caso de mejoras en la puja González de Guadalcanal ganase cien doblas de primer postor y nada en caso contrario. A continuación, que a falta de mejores ofertas durante el mes de diciembre la postura se consideraría nula. No puede extrañar, por tanto, que el rey mandase a los escribanos de cámara poner la renta en almoneda en Sevilla y darla al tercer día en fieldad. Por esta vía quedó en Ruy Sánchez de Huete, para el período 1454-57.

A pesar de ello y en relación con la vuelta del almirante al favor real, producida en marzo de $1455^{8}$, encontramos un nuevo arrendamiento. Su beneficiario fue Rodrigo Álvarez de la Becerra, quien recibió la renta entre mayo de dicho año y fin de $1457^{9}$. En este caso las condiciones eran diferentes y más precisas. El lugarteniente recibía los derechos de guindaje y remate de toneles de todas las mercancías que se cargasen y arrumasen en Sevilla y su archidiócesis. En cuanto a la saca del pan, correspondía al arrendatario la que se hiciese desde Jerez, Sevilla y otros puertos para el arzobispado de Sevilla, obispado de Cádiz y El Condado. También quedaban para él los derechos de las exportaciones hechas hacia Fuenterrabía, San Sebastián y Cartagena, como

desarmador por el Almirante, en nombre de Luis Fernández de Marmolejo, quien ha recibido poder para usar el oficio de almirantazgo por dos años y 10 meses; ADA, 77.30: Traslado de la carta de aprobación hecha en Sevilla el 2 de abril de 1434 por Luis Fernández de marmolejo, Leonor Martínez, su mujer, y Francisco Fernández, su hijo. Cfr. J.M. Calderón Ortega, El Almirantazgo ..., Apéndice n ${ }^{\circ} 13$.

${ }^{4}$ ADA, 7.34: Aguilar del Campo, 21 de junio de 1436.

AGI Justicia, leg. 1143 A: Obligación de Francisca Rodríguez, mujer de Diego Álvarez de la Becerra, como fiadora de mancomún (Sevilla, 14 de diciembre, 1437).

${ }^{5}$ A(rchivo) G(eneral) S(imancas), Escribanía Mayor de Rentas, legs. 4,2 y 7,535.

La renta de 1448 estuvo en manos de Ferrand Sánchez de Toro, escribano de cámara del rey. Vid Ma J. SAnZ y Ma I. Simó, Catálogo de documentos contenidos en los libros de cabildo del Concejo de Sevilla, Sevilla, 1975, nº 1394 (13-XII-1452).

${ }^{6}$ D. Kírschberg Schenck, Catálogo de los Papeles de Mayordomazgo del siglo XV IV (14431454), Sevilla, 2011, $\mathrm{n}^{\circ}$ 1682: Illescas, 29 de mayo de 1449.

7 D. Kírschberg Schenck, Catálogo...IV, no 2090 (7-VII-1452)

${ }^{8}$ D. Kírschberg Schenck, Catálogo....IV, n 2315: notificación al concejo de la restitución de 28 de marzo de 1455 (7-V-1455).

9 ADA, 77.34: recaudo ante Juan Sánchez de Bilbao, escribano real y escribano del almirante y su secretario, sin lugar ni fecha. 
puertos privilegiados. El beneficiario de la renta debía paralizar las licencias del rey para otros lugares hasta que el almirante fuese requerido con tales cartas y se beneficiaba de las penas sobre envíos ilegales. En lo relativo a los quintos, el almirante conservaba los provenientes de armadas y presas pero cedía los relativos a esclavos canarios. También hacía cesión de los derechos de embargo y desembargo de navíos, así como la potestad de nombrar cómitres en Jerez, Cádiz y El Puerto de Santa María cuando él estuviere ausente del arzobispado. Por el contrario, el arrendatario no podía conceder licencias para cargar jabón en Sevilla o su arzobispado, salvo a quienes tuviesen arrendadas las almonas de la ciudad, tanto reales como particulares; y en proporción a su cuota, a fin de que no labrasen más de lo que pagaban de renta. Por último, el almirante se reservaba los oficios y derechos de las armadas reales. Estas condiciones se repiten en el concierto para los años 1463-66, aunque la renta pasó de 2.450 doblas castellanas a 2.600 doblas y 3 neblíes $^{10}$. Su titular fue Juan Barba, vecino de Sevilla.

El arriendo reaparece en 1478, cuando lo detentó Ruy González del Portillo ${ }^{11}$. Su precio ascendió a 1.930 .000 maravedís, aunque en el mismo se incluía, además del oficio con la saca del pan, la receptoría del diezmo del aceite; los 700 quintales de la merced real, valorados en 630.000 maravedís ${ }^{12}$; el traspaso de la licencia para armar dos carabelas con destino a Guinea, con exclusión de la Mina de Oro ${ }^{13}$; y el medio quinto de las presas ${ }^{14}$.

Antes de expirar el plazo de vigencia, el acuerdo fue sustituido por el establecido con Juan de Arauz y Gómez Ferreira por cuatro años, a contar desde el 1 de junio de $1480^{15}$. El precio del arrendamiento era de 1.105 .000 maravedís/año, cantidad que resulta difícil de comparar con la anterior por los cambios introducidos en el contrato. En primer lugar, porque los derechos afectaban también al almirantazgo de Granada, la veinticuatría de Sevilla y la saca del pan, salvo el que se enviara a La Montaña y Vizcaya que se repartiría a medias. A continuación, porque no incluía la receptoría del aceite y reducía a la mitad los derechos por el despacho de carabelas a Guinea.

Tampoco en este caso se completó el arrendamiento, siendo sustituido por un nuevo acuerdo con González del Portillo por seis años, que comenzarían en enero de $1483^{16}$. El precio a pagar eran 900.000 maravedís, 6 cargas de pescado y 1 carga de agua de azahar anual. Se entregaban a cambio los derechos habituales, la saca de pan y la mitad de los quintos del almirante. El tránsito al siglo XVI y, por tanto, al periodo final de nuestro estudio está marcado por el arrendamiento realizado por Juan de Almansa, como principal, y Francisco del Alcázar, como fiador. Su vigencia era de cuatro año, a contar desde el 10 de abril de 1518, y su precio de 910.000 maravedís

\footnotetext{
${ }^{10}$ ADA, 77.34: Villabrágima Broxima (?) 20 de enero de 1463.

${ }^{11}$ ADA, 77-79: Sevilla, 14 de marzo de 1478

12 J. M. Calderón Ortega, El Almirantazgo...p. 300

13 J.M. Calderón Ortega, El Almirantazgo... Apéndice nº 28

${ }^{14}$ Calderón supone que se trata de la mitad del total, "de reciente creación", aunque creemos que debe entenderse como la mitad de la parte que correspondía al almirante, de acuerdo con lo que se argumenta en la notas $\mathrm{n}^{\circ} 27$ y 28 .
}

${ }^{15}$ ADA, 77.88: Toledo, 8 de mayo de 1480.

16 ADA, 77.92: Valladolid, 31 de octubre 1482 
anuales. Los tomadores recibían el grueso de los derechos, incluidos los de la veinticuatría y otras honras anexas al oficio, con exclusión de la mitad de las cosas vedadas y el total de los quintos. En el primero de estos capítulos, la cantidad el almirante era neta, libre de costas,; mientras que en el segundo, los arrendadores recibían una cuarta parte en concepto de gastos de recaudación. También era obligación de los lugartenientes remitir al arrendador los 400.000 maravedís que tenía situados en las rentas de la Casa de Contratación. El acuerdo significa un paso más en la vinculación de los arrendadores, incluido su antecesor Gaspar de Santa Cruz, al ámbito del almojarifazgo ${ }^{17}$.

\section{LAS RENTAS DE LA GUERRA MARÍTIMA}

Volviendo al análisis de las rentas, comenzaremos por las ligadas a la guerra del mar.

\subsection{LA SITUACIÓN INICIAL}

Parte de las ganancias del almirante procedían de su papel como responsable de la flota real. Hasta la primera mitad del siglo XV su participación personal en la misma era habitual, desapareciendo completamente después. En tales ocasiones solía recibir el título de capitán general. En caso de ausencia se hacía representar por un lugarteniente, normalmente un familiar, que recibía el mismo título. Su presencia en la flota, efectiva o por interpuesta persona, era importante desde el punto de vista de los derechos. No en vano, en el informe de Fernando Alfonso a Enrique III, se recoge que «algunos dicen que el almirante non debe haber cosa alguna salvo cuando el fuere por su cuerpo mismo en la flota $»^{18}$. Seguramente es este el origen del distingo entre "flota real" y "flota general" que introducen algunos de los testigos sobre los derechos de los escribanos de armada, al establecer que en el primer caso eran pagados de acuerdo a la norma mientras que en el segundo iban en calidad "ventureros", recibiendo únicamente una participación en las presas ${ }^{19}$. Las concesiones del oficio a Fernán Sánchez de Tovar en $1374^{20}$, a don Alfonso Enríquez en $1405^{21}$ y a su hijo Fadrique en $1426^{22}$ recoge esta realidad con las siguiente fórmula: de todas las ganancias que el almirante hubiere en la flota por la mar que haya el rey dos partes y el almirante el tercio, «yendo por su cuerpo mismo en la flota, aunque la dicha flota o parte de ella se aparte por su mandado o sin su mandado». A renglón seguido las mercedes se refieren a las armadas de menor rango, con las siguientes palabras: otrosí que en todas las galeras

${ }^{17}$ ADA, 78.43: Valladolid, 22 de marzo de 1518.

${ }^{18}$ L. SuÁRez Fernández, Navegación y comercio en el Golfo de Vizcaya. Un estudio sobre la politica marinera de la Casa de Trastámara, Madrid, 1959, Apéndice, nº XIII (8-XI-1397?).

${ }_{19}$ AGS, Estado (Castilla), leg. 1, 2 ${ }^{\circ}, \mathrm{n}^{\circ}$ 122: Información para saber si en las armadas que los reyes hacen por mar ha de haber escribano y que derechos ha de llevar: deposiciones de los testigos de Bilbao (4-VI-1484).

${ }^{20}$ J. M. Calderón Ortega, El Almirantazgo...., Apéndice n ${ }^{\circ} 4$

${ }^{21}$ J. M. Calderón Ortega, El Almirantazgo..., Apéndice n ${ }^{\circ} 6$

22 J. M. Calderón Ortega, El Almirantazgo..., Apéndice no 9 
que yo mandare armar sin flota para ganar, que de la ganancia que yo hubiere, que haya yo las dos partes y el almirante la tercia parte. Esta distinción figuraba ya en Las Partidas, que establecen diferencias entre flota, conjunto de galeras y naves que sirven al rey con gran cantidad de gente, al modo de la hueste terrestre; y armada, corto número de embarcaciones aprestadas para la ocasión ${ }^{23}$. En esta segunda modalidad los ingresos del rey y su almirante serían menores y dependerían de la contribución del monarca como armador ${ }^{24}$. Sin embargo no deben confundirse con el quinto sobre las presas, que venía regulado a continuación. La tripartición entre ingresos de flotas, armadas y quintos sobre presas de particulares se encuentra también en el acuerdo de 1489 entre D. Fadrique e Iñigo de Artieta para que este fuera su lugarteniente ${ }^{25}$.

Los derechos del almirante en la organización de la flota se traducían en una tasa por embarcación aprestada, tal como lo muestra la reclamación del recaudador del almirante al armador de la flota del rey en $1430^{26}$. En dicha fecha los derechos devengados eran 1 marco de plata (2.500 maravedís) por cada galera y 1.100 maravedís por cada carraca, a razón de 12 maravedís por cada uno de los 40 hombres de armas y 7 maravedís por cada uno de sus 90 ballesteros. Su responsabilidad en el pago de los alistados también generaba derechos, aunque la mayoría por vía jurisdiccional. Así queda de manifiesto en el arrendamiento hecho por el recaudador del almirante de la renta "del principal y penas" de quienes recibieron dineros en la tabla del rey para la flota aprestada en Sevilla en el período 1433-36, con las penas de los "silencios" que les hubieren puesto los jueces de armada, todo por 20.00 maravedís ${ }^{27}$. Dicho arrendamiento era fruto de un poder del almirante, acompañado de carta del rey para que el armador de la flota y los escribanos de la tabla diesen la nómina de los galeotes hui$\operatorname{dos}^{28}$. Inicialmente, también era responsabilidad suya el nombramiento de los oficiales que aseguraban la organización administrativa de la flota: armadores, contadores, escribanos y alguaciles; aunque paulatinamente fue sustituido por la acción directa de los monarcas ${ }^{29}$. Esta supervisión no comportaba, al menos en teoría, nuevos ingresos para el almirante, pero le ayudaba en el mantenimiento de su posición personal y en el de su red clientelar. En el mismo sentido, cada vez que organizaba una armada podía liberar a cuatro condenados a muerte, para enrolarlos en las galeras ${ }^{30}$.

${ }^{23}$ Las Siete Partidas del rey Alfonso el Sabio, cotejadas con varios códices antiguos, Madrid, Real. Academia de la Historia, 1807, Segunda Partida, Título XXIV, ley I.

${ }^{24}$ Sobre esta cuestión, véase E. Aznar Vallejo, "La guerra naval en Castilla durante la Baja Edad Media", En la España Medieval 32 (2009), pp. 167-192.

${ }^{25}$ ADA 77.101: Valladolid, 1 de mayo de 1489). Cfr. J. M. CALDERÓN ORTEGA, El almirantazgo..., Apéndice $\mathrm{n}^{\circ} 29$

${ }^{26}$ ADA, 77.25: Sevilla 28 de febrero de 1431.

27 ADA, 77.33: Hecho por Juan Rodríguez de Illescas, vecino de Sevilla en la collación de Santa Cruz y pagador de las villas de Zahara, Cenete y la Torre del Alfaquí, en favor de Juan Fernández de Cuadros, vecino de Sevilla en la collación de San Martín. Sevilla, 13 de septiembre de 1436.

${ }^{28}$ ADA, 77.3: Obligación del escribano Juan Fernández de Sasamón de entregar dichos documentos, depositados por Alfonso Ruiz de Madrigal, cuando fuere requerido para ello. Valladolid, 5 de mayo de 1432.

${ }^{29}$ E. Aznar Vallejo, "La organización de la flota real de Castilla en el siglo XV", La Península Ibérica entre el Mediterráneo y el Atlántico. Siglos XIV-XV, Sevilla-Cádiz, 2006, pp. 323-339.

30 J. M. Calderón Ortega, El Almirantazgo.... Apéndice nº 4; ADA, 77.52: confirmación de los privilegios concedidos en 1405, hecho en Valladolid el 1 de octubre de 1440. 


\subsection{EL CRECIENTE PESO DE LOS QUINTOS}

La habitual ausencia de los almirantes en flotas y armadas, inclinó el peso de estos ingresos hacia el capítulo de quintos. Eran éstos derechos que correspondían al rey, como bienes extraordinarios, y que este compartía con su almirante. Tal merced servía como recompensa vasallática y como estímulo al control de las operaciones de corso efectuadas por particulares. Hay constancia de su donación desde $1374^{31}$. El reparto era idéntico al otorgado en otros apartados: dos tercios y un tercio, aunque en 1475 se elevó a la totalidad ${ }^{32}$. Esta nueva merced resultó efímera, a pesar de haberse hecho por juro de heredad. Ya en 1477 encontramos reclamaciones sobre el quinto real de los bienes enviados desde Canarias y Guinea ${ }^{33}$. Y un año después la reivindicación real incorpora los derechos que en el mismo pertenecían al Almirante ${ }^{34}$.

El disfrute de este gravamen se enfrentó a múltiples dificultades, debidas a las resistencias de los particulares y a la cambiante política de la monarquía. La situación llegó a ser tal, que los reyes hubieron de nombrar a Francisco de Soria juez mero ejecutor para reclamar judicialmente y hacer cobrar los quintos de las presas que correspondían al monarca y al almirante ${ }^{35}$.

Primordialmente, el monarca y su almirante debieron hacer frente a la usurpación señorial de éstos derechos. Contra esta práctica se legisló en las Cortes de 1480, en las que se reafirmó el carácter real y no señorial del derecho ${ }^{36}$. En el caso de Cádiz, tal situación tuvo carácter legal desde 1472 a 1497, al conceder Enrique IV por juro de heredad los quintos y pecios de Cádiz y Rota a don Rodrigo Ponce de León, lo que fue confirmado por los Reyes Católicos en 1476, aunque limitándolo a la vida del marqués por haberse revocado en las Cortes de Toledo ${ }^{37}$. Es posible, incluso que existiera concesión anterior del pretenso Alfonso XII, en nombre de quien el marqués ocupó la ciudad a fines de 1466 o comienzos de $1467^{38}$. Y aún más, pues en 1456 las autoridades concejiles negaron el pago al Almirante, pretextando sus usos y

31 J. M. Calderón Ortega, El Almirantazgo.... Apéndice n ${ }^{\circ}$ 4: merced del oficio de almirante a Fernán Sánchez de Tovar. Segovia, 22 de septiembre de 1374. Las Partidas consignan el derecho de un séptimo para el almirante, sin participación en el quinto real. Vid Las Siete Partidas...Título XXVI, ley XXX...

${ }^{32}$ P. Rufo Ysern, Documentación andaluza en el Registro General del Sello, Huelva, 1996, n 18 : Merced por juro de heredad, en atención de los gastos realizados por el Almirante, de los 2/3 de los quintos de las presas hechas en mares y ríos, que se unen al 1/3 que ya le correspondía (15-II-1475); y $\mathrm{n}^{\circ}$ 131: Confirmación de lo anterior (17-XII-1475) (Esta última también en R. CARANDE Y J. CARRIAZO: El Tumbo de los Reyes Católicos del Concejo de Sevilla, 1968-1971. I, n 59)

${ }_{33}$ P. Rufo Ysern: Documentación andaluza..., $\mathrm{n}^{\circ} 808$ y 809: Para que se entregue el quinto de los esclavos canarios (2-XI-1477). A. De LA TORRE y L. SuÁrez: Documentos referentes a las relaciones con Portugal durante el reinado de los Reyes Católicos. Valladolid, 1958-60, I, nº 69: Para que se entregue el quinto de una carabela portuguesa al Dr. Rodríguez de Lillo (6-XI-1477).

34 P. Rufo Ysern: Documentación andaluza..., $\mathrm{n}^{\circ}$ 1045: Comisión al tesorero González de Guadalajara (9-I-1478).

${ }^{35}$ P. Rufo Ysern: Documentación andaluza..., no 2888 (19-V-1480)

${ }^{36}$ Cortes de los antiguos reinos de León y de Castilla., Tomo IV. Madrid, 1882. Pág. 187: Cortes de Toledo, $\mathrm{n}^{\mathrm{o}} 113$.

${ }^{37}$ A(rchivo) H(istórico) N(acional), Osuna, leg. 183, nº 4 a, b y c.

38 J. SÁnchez Herrero, Cádiz. La ciudad medieval y cristiana, 2ª ed. Córdoba, 1986, p. 113. 
costumbres, así como privilegios de Juan I, y diciendo que si habían pagado el último año la mitad del tercio era "por cuanto la ciudad quiso complacer al dicho señor almirante" 39 .

En otras poblaciones la situación era la misma. En el Puerto de Santa María, el arrendador de las rentas de la villa hizo oídos sordos a la pretensión de los arrendadores del almirantazgo de $1445^{40}$ y el propio almirante hubo de reclamar contra Lorenzo de Padilla, alcalde mayor, por usurpación de rentas ${ }^{41}$. En Lepe, los reyes ordenaron a Pedro de Zúñiga entregar los quintos a sus representantes ${ }^{42}$ y en la expedición de Charles de Valera a Guinea, el marqués de Cádiz se apoderó de los quintos de las carabelas del Puerto de Santa María ${ }^{43}$. Existe además un rosario de reclamaciones contra el incumplimiento de particulares de Palos, Moguer y otras poblaciones, que parecen improbables sin la anuencia de sus autoridades ${ }^{44}$. Aunque tal vez la descripción más vívida de esta situación es la contenida en una carta de Rivandeneira al Almirante. En ella se queja del duque de Medina Sidonia que hace conducir todas las presas que llegan a Palos, Moguer y Sanlúcar a este último puerto, donde no pagan quintos. Los derechos perdidos en ese año, correspondientes a carabelas portuguesas y a moros, superaron los 100.000 maravedís. Y añade: "en el tiempo del rey don Enrique, él y sus secuaces tentaron asaz cosas en perjuicio de este oficio, pero no hicieron ni tentaron las cosas que hoy el señor duque hace en esta ciudad y el marqués de Cádiz en Jerez, el cual lleva todos los quintos que a esa tierra vienen”, en este año dos presas de moros"45. También resulta muy informativo el pulso mantenido entre Gomes de Enebro, receptor real de los quintos de Guinea, y los lugartenientes de D. Pedro de Estúñiga en Lepe. Este último mantuvo que tenía delegación real para recibir dichas rentas, mientras que el primero insistió en estar presente para dar razón de ellas, ya que se le impedía recibirlas ${ }^{46}$.

Tras la vuelta de Cádiz a realengo, la ciudad siguió disfrutando de un régimen particular. Al igual que sucedía en Puerto Real, la mitad de los quintos quedaron para propios, aunque ante la reclamación de los armadores pasaron a éstos ${ }^{47}$.

Esta pugna formaba parte del conflicto entre reyes y señores por las rentas del cargo y descargo en la Baja Andalucía. Ya en 1445 Juan II reaccionó contra la usurpación de tales derechos, alegando que los mismos no podían haber entrado en la donación

${ }^{39}$ A.D.A 77.60: requerimiento de Alfonso de Valladolid, criado del almirante, Cádiz, 11-IX-1456 (Cfr. J. M. CALderón Ortega, El almirantazgo...., Apéndice nº 22).

${ }^{40}$ ADA, 77.47: Requerimiento de Francisco García de Cáceres, vecino de Jerez, por si y en nombre de Isabel Alfón, mujer de Pedro Ruiz de Cáceres, de micer Batista Genovés y Juan Esteban Bello, arrendadores de los derechos que pertenecían a Diego Álvarez de la Becerra. Juan de Zafra, arrendador de la villa, "leyó un trozo y no quiso proseguir". Puerto de Santa María, 13 de abril de 1445.

${ }^{41}$ P. Rufo Ysern, Documentación andaluza ... no 2377: emplazamiento de Padilla ante el Consejo Real (12-X-1480).

${ }^{42}$ Ídem, n ${ }^{\mathrm{o}} 11$ (20-II-1470).

${ }^{43}$ E. Aznar Vallejo, "La expedición de Charles de Valera a Guinea. Precisiones históricas y técnicas", En la España Medieval, 25 (2002), pp. 403-423.

${ }^{44}$ P. Rufo Ysern, Documentación andaluza ..., no $807,808,845,869 \ldots$

${ }^{45}$ ADA, 111.24: Sevilla, 27 de mayo 1478.

${ }^{46}$ ADA, 77.78: Lepe, 14 de enero 1478.

${ }^{47}$ AGS, Registro General del Sello, 25-IV-1485 s.d.-VIII-1494. fol. 2; y 28-VII-1495. 
de tales lugares ${ }^{48}$. Esta referencia alude, sin duda, al caso de Sanlúcar de Barrameda, cuyo almojarifazgo fue concedido a don Juan Alfonso de Guzmán por Alfonso XI y confirmado por Pedro I, no obstante la reclamación de los arrendadores ${ }^{49}$. A pesar de la reclamación de Juan II, su hijo concedió en 1469 idénticos derechos en Lepe, Ayamonte, La Redondela y Huelva ${ }^{50}$.

El conflicto fue largo y el triunfo de la corona tardó en llegar. En 1479 se renovó la orden para que todas las operaciones portuarias se hicieran con licencia de los almojarifes, salvo las de Sanlúcar de Barrameda ${ }^{51}$. No obstante lo cual, diez años después se comisionó al licenciado Balboa, del Consejo de la Hermandad, para que hiciese pesquisa sobre los puertos abiertos en Cádiz, Gibraltar, Sanlúcar, Puerto de Santa María, Palos, Moguer, Huelva, Vejer, Rota, Ayamonte, La Redondela y otros lugares del arzobispado de Sevilla y obispado de Cádiz, desde la raya con Portugal hasta Gibraltar ${ }^{52}$. Y en 1491, se comisionó al licenciado Coalla para que hiciese nueva información sobre los citados puertos ${ }^{53}$. El año siguiente se ganó el pleito con la casa de Medina Sidonia ${ }^{54}$. En 1493, se dio nueva comisión al licenciado Balboa, en este caso exclusiva para los puertos de Rota y Chipiona ${ }^{55}$. Este último litigio no fue resuelto a favor de la monarquía hasta $1503^{56}$.

En Canarias, la oposición señorial tomó como base la interpretación de la merced hecha a Jean de Béthencourt en 1403, en la que Enrique III le eximió de pagar quinto por las mercancías enviadas desde el Archipiélago ${ }^{57}$. Tal medida se orientaba a la incorporación de las Islas al marco fiscal del Reino, dado que sus productos sólo debían pagar almirantazgo y alcabalas "como cualquier otra ropa de mercaderes". Ahora bien, la mayoría de los productos comercializados no procedía de la producción local sino de las depredaciones en las islas aún por conquistar, integradas básicamente por esclavos. Así lo reconoce la citada sobrecarta, en la que el señor solicita que

${ }^{48}$ AGS, Cámara de Castilla (Diversos), leg. 3-2, no 60: reclamación real y condiciones del arrendamiento de las rentas de mercaderes, almonayma y Berbería por 6 años, entre las que se cuenta la de no cargar o descargar en los puertos del arzobispado, especialmente en los de señorío, sin licencia de los arrendadores (6-VI-1455).

${ }^{49}$ AHN, Osuna, leg. 35, no 52: Traslado autorizado (Osuna, 1-IV-1512) de la confirmación de Pedro I (Sevilla, 23-I-1351) de la carta de su padre (Sevilla, 9-VIII-1327). A pesar de ello, la pugna entre señores y almojarifes continuó. El resultado fue favorable a los señores, que recibieron diversas confirmaciones y, según parece, una nueva concesión de Enrique IV en 1460. Vid los detalles en A. Moreno Ollero, Sanlúcar de Barrameda a fines de la Edad Media, Cádiz, 1983, pp. 198-99.

${ }^{50}$ La situación de estas poblaciones puede en M. A. LADERo QuesADA, "El señorío de Lepe y Ayamonte a finales del siglo XV: mayorazgo, valor y rentas", en Los señores de Andalucía, Cádiz, 1988, pp. 213-227.

${ }^{51}$ R. Carande y J. M. Carriazo, Tumbo de los Reyes Católicos del Concejo de Sevilla, Sevilla, 1929-71. II, pp. 376-378 (I-383, 12-II-1479). El privilegio de Sanlúcar fue revocado por la reina Juana y restaurado por Fernando el Católico. Vid A. Moreno Ollero, Sanlúcar de Barrameda ... p. 199.

${ }^{52}$ AGS, Registro General del Sello, 4 de junio de 1489, fol. 153.

${ }^{53}$ AGS, Registro General del Sello, 20 de abril de 1491, fol. 79.

${ }^{54}$ M. A. Ladero Quesada, “Almojarifazgo sevillano y comercio exterior de Andalucía”, Anuario de Historia Económica y Social, II (1969), p106, nota n 48.

${ }^{55}$ AHN, Osuna leg. 183, $n^{\circ} 4$ bis.

${ }^{56}$ Vid nota $\mathrm{n}^{\circ} 48$.

57 E. Aznar Vallejo, Pesquisa de Cabitos, Las Palmas de Gran Canaria, 1990. Parte Documental, II $\mathrm{n}^{\mathrm{o}} 7$ : Sobrecarta, a petición de Fernán Peraza, de la exención de quintos. 
no se lleve quintos sobre cueros de cabras y cabrones, sebo, y canarios y canarias, a lo que el rey apostilla "se entiende el quinto ser de los dichos canarios, porque de otras mercaderías no se acostumbra levar quintos, mayormente que el dicho Ferrand Peraza ha hecho y face la guerra e conquista a los dichos canarios a su propia despensa". Esto no es óbice para que en los arrendamientos celebrados entre 1434 y 1466 se mencionen los quintos de Canarias y para que, como se verá más adelante, uno de los testigos del pleito entre Sevilla y el almirantazgo deponga que los señores de Canarias se beneficiaban de régimen aligerado. En cualquier caso, los reyes reivindicaron la titularidad de los quintos al incorporar Gran Canaria, La Palma y Tenerife a realengo ${ }^{58}$, aunque cedieron parte de sus ingresos a particulares, comenzando por los propios señores. Éstos obtuvieron autorización para realizar presas en Tenerife y La Palma, mediante el pago de la veintena ${ }^{59}$.

La oposición a los quintos se extendió al reino de Granada antes y después de la concesión del almirantazgo privativo. El diferendo arranca con la real cédula de 15 de agosto de 1491, que concedía al almirante el medio quinto de todas las presas de moros y mercancías de buena guerra, no obstante las mercedes sobre la parte correspondiente a los reyes. En virtud de la misma se produjeron diversas reclamaciones de pago $^{60}$. A la primera de ella, los mercaderes de Almería respondieron que no estaban obligados porque se les requería con una real cédula de 1491, válida durante la conquista del reino; porque el Almirante lo era de Castilla y no de Granada; y porque no se solía hacer salvo que se llevase la cabalgada a algún puerto de Castilla ${ }^{61}$. La réplica del representante del Almirante adujo que la posible merced de franqueza correspondía a las fustas de más de doce bancos -lo que no era el caso- y que la misma afectaba a los derechos del rey, no al medio quinto del Almirante ${ }^{62}$. La otra reclamación de 1495 fue rechazada por vecinos de Málaga, por no ser costumbre en el reino de Granada pagar medio quinto ni otros derechos ${ }^{63}$.

Resulta difícil explicar el paso del tradicional tercio del almirante al medio quinto recogido en esta documentación. En una primera lectura parece ligarse al hecho de la guerra, tal como se desprende de las argumentaciones de las partes. Pero la

${ }^{58}$ Biblioteca Academia de la Historia, Colección Salazar y Castro, M-11, fols. 108-129 vto.: Capitulación entre la Corona y los señores, en traslados presentados por Sancho de Herrera en la Chancillería de Granada (18-XII-1526). Publicado en E. Aznar Vallejo, "La transmisión del señorío de Canarias en el siglo XV. Nuevos documentos y nuevas perspectivas", Boletín de la real Academia de la Historia, CCIV-II, pp. 221-259.

${ }^{59}$ Ibídem.

${ }^{60}$ ADA,77.107: Francisco de Villadiego, apoderado del Almirante, requiere a Juan y Alfonso de Alanís, mercaderes de Almería, para que le paguen el 1/2 quinto de una presa (11 moros). Va inserta R. C. de 15 de agosto de 1491, para que se pague el 1/2 quinto (25-II-1495); ADA, 77.108: Reiteración del requerimiento anterior ante el corregidor de Almería (28-II-1495); y ADA, 78.23: Requerimiento del lugarteniente de Almirante en Málaga al teniente de corregidor de dicha ciudad para que se Pedro de Vera pague el medio quinto de presas y esclavos. Van incorporados dos reales cédulas: la primera de 10-V-1490, para que pague al almirante el medio quinto de lo que trajere de Canaria; y la segunda de 17-II-1492, para que se le acudiese con el medio quinto de las presas como le acuden en los puertos del Andalucía).

${ }^{61}$ ADA,77.107.

${ }^{62}$ ADA,77.107.

${ }^{63}$ ADA,77.107. 
citada real cédula no alude a tal hecho y reclama que se guarde un uso considerado "tradicional" ${ }^{64}$. Por otra parte, conocemos reclamaciones de este derecho en $1504^{65}$, $1512^{66}$ y $1514^{67}$. Cabe añadir, que la documentación alude también a Canarias y consigna que el pago es idéntico a "como le acuden en los puertos del Andalucía" ${ }^{\circ}$. A mayor abundamiento, en el tránsito de los años 80 a los 90 se generaliza en todos los ámbitos la referencia al medio quinto del almirante. Parece tratarse de una elevación del cupo del almirante, acorde con la concesión de igual cantidad a determinados concejos o particulares, aunque la falta de cuentas y de concesión expresa hace difícil seguir el proceso. Durante los tres primeros cuartos del siglo XV no hay dudas en cuanto al reparto, que es de un tercio para el almirante ${ }^{69}$. A partir de entonces, los repartos que conocemos apuntan en la dirección señalada ${ }^{70}$. Este cambio sin respaldo documental explica las dudas de los testigos, incluidos los del almirante, en el pleito que le enfrentó a Sevilla. En él reclamó la mitad del quinto de las presas "por privilegio y costumbre", aunque los jueces anotaron que el privilegio sólo le concedía el tercio. Sus testigos intentaron conferir antigüedad a tal pretensión, alegando una práctica entre 40 y 15 o menos años, aunque no se mostraron unánimes en este punto ${ }^{71}$.

A las dificultades de tipo general que hemos mencionado, hay que unir las propias de las conflictivas relaciones en el mar. Sirva de ejemplo el relato de Rivandeneira al Almirante sobre la captura de una carraca genovesa de 500 toneles durante la guerra

${ }^{64}$ ADA, 77.104: Real sobre Granada, 15-VIII-1491.

${ }^{65}$ ADA, 78.5: Requerimiento del Almirante a Juan Gaitán, Corregidor de Málaga, sobre el medio quinto que le correspondía de una presa y cabalgada hecha por el capitán Martín Hernández Galindo hacía 8 o 9 meses en El Estrecho, en la que se obtuvieron 14 fustas de moros y otros bienes (Málaga, 17-VIII-1504).

${ }^{66}$ ADA, 78.19: Real cédula a Juan de Leiva, capitán mayor de la mar, para que acuda al Almirante con el medio quinto de las presas. (Santa Fe, 17-II-1492, inserta en una sobrecarta de 1512).

${ }^{67}$ La oposición al medio quinto persistía en 1514. Vid. M ${ }^{a}$ T. López Beltrán, El puerto de Málaga en la transición a los Tiempos Modernos, Málaga, 1986, p. 198.

${ }^{68} \mathrm{Vid}$. Nota 54.

${ }^{69}$ Citamos, a modo de ejemplo, AHN, Osuna, leg. 289 n ${ }^{\circ}$ 4: Poder de Diego Fernández para cobrar a $\mathrm{D}^{\mathrm{a}}$ Isabel de Guzmán, condesa de Ledesma, 13 moros que él había tomado para el Rey, como quinto de los 63 esclavos y 2 fustas apresadas por pescadores, que la condesa tomó en secuestro (Sevilla, 21-X1435). Y recibo [en carpeta 48, $\mathrm{n}^{\circ} 8$ ] de nueve, pues los otros 4 se quedaron con don Fadrique, almirante de Castilla, por su quinto). B(iblioteca) N(acional) - Manuscritos, $\mathrm{n}^{\mathrm{o}} 17789$ Diferentes noticias sobre derechos... antiguos almirantes... por José de Rojas y Contreras: Borrador de diferentes noticias... $\mathrm{n}^{\circ} 21$ : requerimiento de Pedro Ferrera, teniente de almirante en Jerez de la Frontera, a Fernando Gattica, Diego de Torres y Bartolomé de Casas, sobre el cobro de la tercera parte del quinto de 42 moros y moras, que les correspondieron de una presa que hicieron, con vecinos de Cádiz y Puerto de Santa María, pasado el río de Las Lagunas (4-IX-1467).

${ }^{70}$ Citamos, a modo de ejemplo, A. D. A. 77.107: Francisco de Villadiego, apoderado del Almirante, requiere a Juan y Alfonso de Alanís, mercaderes de Almería, para que le paguen un moro y medio quinto de otro en concepto de medio quinto de una presa de 11 moros grandes y pequeños (25-II-1495). A.G.S, Consejo Real, leg. 5-2: en la cuenta de la cabalgada de Pedro Estopiñán, el almirante demandó medio quinto. Por ejemplo de los 717.100 maravedís que correspondieron a los vasallos del duque, reclamó $71.710 \mathrm{mrs}$. (1498).

${ }^{71}$ AGI, Justicia, leg. 1143 A: El interrogatorio en que consta tal pretensión fue presentado en Sevilla el 13 de diciembre de 1484. 
luso-castellana ${ }^{72}$. Los afectados reclamaron la devolución de la nave por tener seguro real, mientras que los integrantes de la flota la condujeron a Sanlúcar, donde comenzó la pugna por su atribución. En la disputa participaron el doctor Lillo y el cronista Alonso de Palencia, comisionados regios para la organización de la flota; Álvaro de Nava, capitán de la misma; el representante del almirante; y mosén Gener, capitán de las galeras aragonesas integradas en la flota. Éste último llegó a alzarse con la carraca, pretextando ser vasallo del rey de Aragón y criado del conde de Prades; por lo que hubo de ser reducido por las armas.

Otro tema que suscitó la oposición de particulares fue el de la equiparación entre presas y cabalgadas a la hora de quintar. Estas operaciones estaban separadas por el medio en que se desarrollaban: el mar, en el primer caso, y la tierra, en el segundo; pero a menudo compartían protagonistas y podían ser episodios de una misma expedición. Estas similitudes se daban especialmente en la guerra de allende, tal como señala la documentación al unir "presas e cabalgadas que de tierra de moros, enemigos de la nuestra santa fe, se troxesen" "73. Ello explica que la regulación monárquica que conocemos se refiera a la misma. En 1503 se ordenó al Almirante no cobrar quintos sobre cabalgadas allende, a fin de incentivar la realización de este tipo de guerra ${ }^{74}$. En claro contraste con ésta última medida, en 1522 se recordó a las autoridades de Orán, Bujía y Mazalquivir la obligación de pagar los quintos de las cabalgadas de moros ${ }^{75}$.

Tras su reconquista, el reino de Granada se convirtió en importante foco para estas acciones, que llegaron a constituir un modo de vida. Los datos de puerto de Málaga son escasos para nuestro período de estudio, pero aportan luz sobre algunos de sus aspectos organizativos ${ }^{76}$. Entre ellos, la exención temporal de quintos como medio de alentar tales empresas ${ }^{77}$. Otros datos algo posteriores muestran la falta de separación clara entre presas y cabalgadas y la reiterada presencia de algunos propietarios en estas actividades depredatorias. La situación debió de ser similar en Almería, Marbella, Vélez-Málaga y otros puertos del antiguo sultanato.

Lo anterior no es óbice para que los puertos del Baja Andalucía siguieran participando en este tipo de actividades, tanto en esta Berbería de Levante como en su

72 ADA, 111-24 (Sevilla, 27-V-1478). Detalles de la citada captura en E. Aznar Vallejo, "La expedición de Charles de Valera a Guinea. Precisiones históricas y técnicas", En la España Medieval, 25 (2002), pp. 403-423.

73 ADA, 77.60 Cádiz, 11 de septiembre de 1456. Cfr. J. M. Calderón Ortega, El Almirantazgo..., Apéndice $\mathrm{n}^{\circ} 22$.

74 ADA, 78.3: Alcalá de Henares, 23 de junio de 1503).

${ }^{75}$ B(iblioteca) N(acional) - Manuscritos, $\mathrm{n}^{\circ} 17789$ Diferentes noticias sobre derechos... antiguos almirantes... por José de Rojas y Contreras: Borrador de diferentes noticias... n ${ }^{\circ} 42$ (27-III y 8-VIII1522).

${ }^{76} \mathrm{M}^{\mathrm{a}}$. T. López Beltrán, "Cabalgadas en el mar de Alborán en tiempos de los Reyes Católicos", miscelánea de Estudios Árabes y Hebraicos (Sección Árabe-Islam, 50 (2001) pp. 169-186.

${ }_{77} \mathrm{M}^{\mathrm{a}}$. T. López Beltrán, “Cabalgadas... p. 176: reclamación de 51 vecinos de Málaga contra el regidor Alonso Cherino, que pretendía quedarse con el quinto de un cárabo, cargado de hierro y con ocho moros, que fue tomado Allende; cuando la Corona había hecho merced de dicho ingreso a cualquier persona que tomara navíos musulmanes en las costas de Granada o de Berbería (16-VIII-1491). (La reclamación y la merced pueden verse también en J. M. Ruiz Povedano, Catálogo de documentos contenidos en el primer libro de Actas Capitulares (1487-1494) del Archivo Municipal de Málaga, Málaga, 1998, nº 147 y 152). 
homónima de Poniente ${ }^{78}$. Uno de sus ejemplos resulta paradigmático del enfrentamiento entre almirantazgo y particulares por este gravamen. Se trata del largo pleito que enfrentó a Pedro de Estupiñán y luego a sus herederos con las autoridades por los derechos de una cabalgada hecha cerca de Orán en 1498, en la que se obtuvieron 250 cautivos $^{79}$. Sus orígenes se encuentran en la reclamación presentada por Luis Ortiz de Gatica, lugarteniente de almirante en Jerez, que obtuvo del alcalde mayor de la ciudad mandamiento ejecutorio a su favor. Este auto fue apelado ante el Consejo, lo que dio lugar a una interesante probanza. En ella, los testigos del reclamante señalaron que Estupiñán fue como capitán del duque de Medina Sidonia, quien prometió a los participantes no pedirles quinto ni otra cosa, excepto los gastos de navíos y bastimentos. Añadieron que la presa se hizo en tierra, en la aldea de Bucifar, lugar en el que el almirante carecía de derechos; que en otras presas hechas desde Melilla o desde Jerez no se pagaron quintos y en los casos que los tenientes de almirante los reclamaron fueron desautorizados por los jueces; que el duque tenía los quintos por mar y tierra por concesión real; y que los ingresos de la cabalgadas fueron exiguos.

La parte contraria presentó una cuenta de la armada, que contradice el escaso valor que le asignaron los participantes. Según ésta, a los portugueses y a los vasallos del duque les correspondieron 717.100 maravedís, de los que 71.710 pertenecían al almirante como medio quinto. El resto suponía 991.833 maravedís, aunque algunas cantidades estaban pendientes de "averiguar" en relación al quinto.

La recaudación del quinto también podía verse afectada por la política general de la monarquía. Es el caso de la conquista realenga de Canarias. Así, en la segunda capitulación para la incorporación de Gran Canaria se acordó que durante diez años ni el Almirante ni sus lugartenientes llevasen derechos sobre las pesquerías y presas hechas en la isla, renunciando los reyes a los quintos sobre cueros, sebo, esclavos y armazón y sobre las presas hechas en islas de infieles, salvo en la Mina de $\mathrm{Oro}^{80}$. Al mismo tiempo, se ordenó al almirante que no percibiese derechos sobre el pan enviado a Gran Canaria ni sobre los esclavos que desde allí se trajesen mientras que durase la conquista, ya que esta pertenecía a la Corona ${ }^{81}$. A pesar de ello, Pedro de Vera recibió 4 años más tarde la mitad del quinto real sobre las presas "de la Gran Canaria e de las que se ficieren en las islas de Tenerife e La Palma e la Berbería" ${ }^{2}$, lo cual no deja de sorprender si tenemos en cuenta su participación en la citada capitulación. El valor de dicho medio quinto en el período diciembre de 1484 y abril de 1486 fue de 69.602 maravedís $^{83}$. Ya hemos visto, como en 1490 el almirante obtuvo real cédula para que Pedro de Vera pagase el medio quinto de lo que trajere del Archipiélago ${ }^{84}$. A pesar

${ }^{78}$ Un panorama sobre esta cuestión puede verse en E. AzNAR VALLEJo, "La guerra de allende. Condicionantes mentales y técnicos de la nueva frontera", XXI Semana de Estudios Medievales de Estella (Guerra y diplomacia en la Europa Occidental, 1280-1480), Pamplona, 2005, pp. 83-115.

${ }^{79}$ A.G.S, Consejo Real, leg. 5-2

${ }^{80}$ E. Aznar Vallejo, Documentos Canarios en el Registro del Sello (1476-1517), San Cristóbal de La Laguna, 1981, nº 52 (s.d.-II-1480).

${ }^{81}$ E. Aznar Vallejo, Documentos ... no 49 (4-II-1480).

${ }^{82}$ M. A. Ladero Quesada, "Las cuentas de la conquista de Gran Canaria", Anuario de Estudios Atlánticos 12 (1966), pp. 79-80 (23-VIII-1484).

${ }^{83}$ M. A. Ladero Quesada,... pp. 80-89: cuenta de Antonio de Arévalo.

${ }^{84}$ Vid. Nota $n^{\circ} 54$. 
de tales mercedes, Alonso de Lugo recibió al concertar la conquista de La Palma la mitad de los quintos de las cabalgadas efectuadas en Tenerife y Berbería, debiendo tomar de la otra mitad los 700.000 maravedís que conforme a lo asentado había de cobrar por dicha conquista ${ }^{85}$. También recibió como ayuda los quintos pertenecientes a la Corona sobre los cautivos, ganados y demás bienes de los canarios de La Palma ${ }^{86}$. Sin embargo, la cambiante actitud de la monarquía se traducía en inseguridad jurídica para los beneficiarios. Por ello, Alonso de Lugo solicitó se hiciese información sobre los quintos de La Palma, pues temía que el almirante le exigiese la mitad de los mismos, cuando los enviase a vender a Sevilla y otros puertos de Andalucía ${ }^{87}$. También pidió que se averiguase si los quintos de la conquista de Gran Canaria habían pagado la mitad al almirante y con qué títulos. El rey confió la pesquisa al asistente de Sevilla y ordenó que mientras durase la misma se registrasen las presas ante escribano. Lugo debía dar fianzas por ellas, pero no se le podría solicitar pago hasta la resolución real. Como en tantas ocasiones, desconocemos si existió dictamen y, en caso de haberlo, su sentido.

La recaudación de los quintos de la Berbería de Poniente, entre los cabos de Aguer y Bojador, siguió un proceso similar al desarrollado en las Canarias de realengo: reserva real y cesión parcial a particulares. A las concesiones ya mencionadas, hay que sumar otras. En 1499, el asiento entre la Corona y Alonso de Lugo para la ocupación del territorio otorgó a éste la mitad de los quintos reales ${ }^{88}$. Como tal acuerdo no llegó a ejecutarse, en 1511 el mismo personaje obtuvo la mitad de los quintos de las expediciones realizadas por los vecinos de Tenerife y La Palma ${ }^{89}$. A esto hay que añadir que desde 1519 las cabalgadas dirigidas por el citado Alonso de Lugo o su hijo Pedro quedaron exentos del quinto rea ${ }^{90}$. A pesar de la reserva real, los señores siguieron percibiendo rentas sobre tales cabalgadas mediante la exoneración de pago de los mantenimientos y provisiones sacados para la expedición a cambio de percibir un quinto de lo obtenido, quedando los cuatros quintos restantes para los armadores ${ }^{91}$. Los reyes se opusieron a dichas prácticas y reclamaron los derechos correspondientes a tales expediciones, conforme a lo que se hacía en los territorios realengos ${ }^{92}$. La regulación de las cabalgadas canarias parece distinta de la que ordenaba las empresas andaluzas, tal como se desprende del fracasado intento de vecinos de Cádiz de eludir el pago del quinto real de una presa vendida en Gran Canaria, escudándose en sus privilegios $^{93}$. Tras la guerra con Portugal, la zona de cabalgadas se amplió a regiones

${ }^{85}$ E. Aznar Vallejo, Documentos... n ${ }^{\circ} 336$ (13-VII-1492).

${ }^{86}$ E. Aznar Vallejo, Documentos... no 335 (13-VII-1492).

${ }^{87}$ Idem, $\mathrm{n}^{\circ} 351$ (28-II-1493).

${ }^{88}$ AGS, Cámara de Castilla (Diversos), leg. 9, nº 5 (2-X-1499).

${ }^{89}$ E. Aznar y otros, Documentos canarios en el Registro del Sello (1518-1525), San Cristóbal de La Laguna, 1991, $\mathrm{n}^{\circ}$ 241: Confirmación de tal merced (24-XII-1520).

${ }^{90}$ E. Aznar y otros, Documentos Canarios..., no 136 (17-VIII-1519).

${ }^{91}$ A. Rumeu de Armas, "El origen de las Islas Canarias del licenciado Luis Melián de Betancor", Anuario de Estudios Atlánticos, XXIV (1978), p. 78.

${ }^{92}$ Ibídem.

${ }^{93}$ E. González y M. Marrero, Protocolo del escribano Hernán Guerra, San Cristóbal de La Laguna, 1958, nº 940 (3-X-1509). 
bajo jurisdicción lusitana, mediando el acuerdo entre ambos reinos ${ }^{94}$.

En cualquier caso, no conocemos reclamaciones del almirante sobre estas operaciones, seguramente por carecer de medios en las Islas. Tal vez esta fuese la causa de que en 1525 se pretendiese ampliar el ámbito del almirantazgo a Gran Canaria, Tenerife y La Palma, alegando haber pasado 25 años de franquicia poblacional y ser las islas anejas a la ciudad y arzobispado de Sevilla ${ }^{95}$. Tal pretensión se fundamentó en la información de Pedro Gallego, vecino de Tenerife, autor en 1518 de un aviso similar sobre la cobranza de almojarifazgo en dichas islas y de tercias en las islas de señorío, que prosperó en el primer caso y fracasó en el segundo ${ }^{96}$. En lo relativo a los derechos de almirantazgo, la tentativa no llegó a buen puerto, aunque muestra el influjo del marco fiscal sevillano en el Archipiélago, visible también en el almojarifazgo, haber del peso, etc. Y ello a pesar de que la exención anterior no afectaba a los derechos de carga y descarga sino a los relativos a productos remitidos o recibidos durante la conquista y, en el caso de Gran Canaria, durante los diez años que siguieron a la mis$\mathrm{ma}^{97}$. En el caso de la creación de alcaldías y escribanías de sacas y cosas vedadas en Canarias de las islas encontramos la misma laxitud por parte del almirantazgo, lo que dejó solos a los concejos en la defensa de sus franquicias ${ }^{98}$.

La guerra de sucesión en Castilla puso en entredicho el reparto de África establecido con los portugueses y alteró, por tanto, el aprovechamiento económico de dichas regiones. En sus inicios, los Reyes Católicos reclamaron la conquista de "África y Guinea" y la regulación de todas las actividades que en ellas se realizasen ${ }^{99}$. Su acción se dirigió fundamentalmente hacia la segunda zona, en razón del daño que podía causar en los interese económicos lusitanos. En la vertiente militar de presas y cabalgadas, se concedió licencia general para armar contra contrarios, incluyendo en ella la liberación de quintos, excepto lo de la Mina y Canaria ${ }^{100}$. En virtud de esta autorización, se produjeron diversos apresamientos de naos y carabelas portugue$\mathrm{sas}^{101}$. La licencia sirvió, por otra parte, para organizar expediciones hacia las zonas

${ }^{94}$ E. Aznar Vallejo, La guerra de allende..., pp. 97 y ss.

${ }^{95}$ ADA, 79.7: Dueñas, 14 de diciembre de 1525.

${ }^{96}$ E. Aznar Vallejo, La integración de las Islas Canarias en la Corona de Castilla (1478-1526, Las Palmas de Gran Canaria, 2009, $3^{\text {a }}$ ed., p. 139; y "La Gomera en el tránsito del siglo XV al XVI. Aspectos económicos", V Coloquio de Historia Canario-Americana, Las Palmas de Gran Canaria, 1985, pp. 403-420.

97 E. Aznar Vallejo: Documentos..., no 49, 52, 338, 351, 869.

98 E. Aznar VAllejo, La integración ..., pp. 40-41.

${ }^{99}$ Una visión general sobre esta cuestión en E. AzNAR VALLEJo, "Estado y colonización en la Baja Edad Media. El caso de Castilla”, En la España Medieval 11 (1988), p. 14 y ss.

${ }^{100}$ M. Fernández De Navarrete: Colección de los viajes que hicieron por mar los españoles desde finales del siglo XV. Madrid, 1954. I b, Apéndice n 5 (7-V-1479).

E. Aznar Vallejo: Documentos..., $\mathrm{n}^{\circ}$ 34: seguro a favor de Alfonso de Salvatierra quien se ha ordenado armar un carracón y dos carabelas para hacer la guerra a Portugal, concediéndole las presas que hiciese, salvo el quinto de lo de La Mina y Canaria (7-VII-1479).

${ }^{101}$ Citamos, a modo de ejemplo, E. Aznar VAlLejo: Documentos .... $\mathrm{n}^{\circ}$ 28: carabela portuguesa cargada de oro, malagueta, bacines y otras mercancías, que procedente de la Mina de Oro fue apresada en Lanzarote. Orden de que se pague a Alfonso González de Guadalajara (10-VIII-1478). 
de soberanía portuguesa sin incorporarse a la flota real ${ }^{102}$. En salvaguarda de sus intereses, los monarcas comisionaron a Alfonso González de Guadalajara para recaudar los quintos obtenidos contra moros y portugueses, así por mar como en el reino de Granada y Guinea. De esta labor se excluía a otras personas; salvo el almirante, que podía recaudar directamente su parte. En la real cédula se ordenaba al almirante y al alcaide de los alcázares colaborar en el prendimiento de los bienes y personas de los inobedientes, el primero por los mares o ríos y el segundo por tierra ${ }^{103}$. En el caso de Guinea y, en especial, la Mina de Oro, también se concedieron licencias reales, como la ya citada a favor del almirante. Podían otorgarse con o sin exoneración de quintos, aunque conviene precisar que los reyes también recibían quintos de las operaciones comerciales en la zona (rescates) y que resulta difícil discernir en las dispensas cuál era la naturaleza de la expedición. Excepcionalmente, conocemos exoneración de quintos por parte del almirante ${ }^{104}$.

Acabada la contienda, los monarcas castellanos ordenaron -con algún momento de vacilación ${ }^{105}$ - pagar tales derechos a sus homólogos portugueses ${ }^{106} \mathrm{y}$ encargaron a Jorge de Tordesillas, lugarteniente de almirante, el control de los quintos hasta tanto se cerrasen las negociaciones con el rey portugués ${ }^{107}$. A partir de entonces, las cabalgadas quedaron circunscritas a las zonas de soberanía castellana o de utilización conjunta con los lusitanos. También se intentó someterlas a un mayor control, mediante un régimen de licencias ${ }^{108} \mathrm{y}$ de concentración de los lugares de inspección fiscal ${ }^{109}$; aunque, como hemos visto, con poco éxito.

\section{EL CONTROL DE LOS PUERTOS}

También correspondía al almirantazgo la inspección de los puertos y de las operaciones que en ellos se desarrollaban. Tal cometido generaba los denominados derechos de almirantazgo, que eran refundición de antiguos gravámenes, como los de anclaje, lastre y despacho. Los mismos están reunidos en diversos aranceles, que

102 A. De la Torre y L. Suarez: Documentos Portugal... I, no 65: Comisión sobre las carabelas tomadas por vecinos de Palos a portugueses que venían de Guinea, por haber ido "contra los defendimientos" (13-IX-1477).

${ }^{103}$ P. Rufo Ysern, Documentación andaluza ... no 1045 (9-I-1478).

104 A. De la Torre y L. SuÁrez, Documentos Portugal..., II, $\mathrm{n}^{\circ}$ 204: seguro a las carabelas de Diego Díaz y Alfonso de Ávila, mercaderes, en el que se ordena guardar la cesión de la cuarta parte del quinto del almirante (sd.-II-1480).

${ }^{105}$ P. Rufo Ysern, Documentación andaluza..., n 2216: Poder a Álvaro de Medina para recaudar la tercera parte del oro y otras mercancías de la carabela Buenavista y tenerlo en secuestro hasta que sus majestades decidan (5-IV-1480).

106 A. De la Torre y L. SuÁrez, Documentos Portugal..., II, nº 196, 213, 239, 241, 246 y 255.

107 A. De la Torre y L. SuÁrez, Documentos Portugal...II, no 201 (3-II-1480).

108 AGS, Registro General del Sello, 14-VII-1492, fol. 162: para que el juez de residencia de Jerez impida a Juan de Olmedo, vecino de Puerto Real, hacer cabalgadas Allende, porque sólo Pedro Patiño tenía licencia real.

109 A. Rumeu de Armas, España en el África Atlántica, Madrid, $1957\left(1^{\text {a }}\right)$, II, doc. $n^{\circ}$ 10: obligación general de quintar todas las presas hechas en el mar, en tierra de moros o en otras partes, en Puerto Real (23-II-1486). También en R. Carande y J. Carriazo: Tumbo..., III, 74. 
recogen la evolución económica del reino y los cambios de equilibrio entre las partes. Ello no obsta para que en algunos casos la documentación conserve los antiguos derechos. Es el caso, por ejemplo, de la reserva de un tercio de la carga a precio de flete, de acuerdo con la tradicional fórmula de la renta de despacho, recogida en el nombramiento de Íñigo de Artieta como lugarteniente ${ }^{110}$.

\subsection{EL PUNTO DE PARTIDA}

El primero de dichos aranceles es de comienzos del siglo XIV y grava el tráfico del puerto de Sevilla atendiendo a dos categorías: productos y embarcaciones. ${ }^{111}$ En el primer caso, los artículos sometidos a pago son diversos tipos de pesca (sardina, sarda, ballena, atún, sábalos, pijotas, y coquinas) y fruta (manzanas). En todos los casos se trata de importaciones destinadas al consumo y pagadas en especie. La norma es prolija y recoge las más diversas circunstancias. En primer lugar, del sistema de conservación. Las sardinas y sardas podían comercializarse frescas, saladas o arencadas; los sábalos y coquinas frescos o salados; y los atunes frescos, salados o en mojama. A continuación del despiece del animal. En los atunes se distinguía: badanes y lomos; $\mathrm{y}$ en las ballenas cuerpo y lengua. La regulación no olvida los diversos sistemas de almacenamiento. Las sardinas y sardas podían transportarse en canastas, seras o en pilas; los sábalos en jarras o en pilas; y los atunes en costales. También enumera las embarcaciones utilizadas: naos, bajeles y barcas. En cualquier caso, estos parámetros no intervienen en el precio a pagar. Pueden hacerlo, en cambio, la vecindad de los interesados y el origen de los productos. En la importación de atunes se distingue entre vecinos y albarranes, estando los primeros exentos y los segundos obligados a pagar, tanto si son únicos propietarios como si son asociados. Y en la traída de pijotas se discrimina entre barcas de portugueses, que pagan dos unidades, y las de castellanos, que pagan una, salvo que estos las pesquen en el Algarbe, en cuyo caso no deben nada.

El segundo epígrafe se refiere al ancoraje de las embarcaciones. En este caso se trata de buques dedicados a tráficos comerciales de mayor envergadura. Entre ellos se produce una gradación en el pago. En aquellos que cargan toneles, las tasas son las siguientes. La carraca paga dos doblas; las naos de más de 50 toneles dan una; las naos menores pagan "por tonelada"; los navíos y barcas provistas de batel o góndola (carroza) también tributan por tonelada; y los navíos y barcas sin góndola o batel no deben nada. En cuanto a otros tipos, los bajeles y barcas que transportan atún están obligados a pagar una jarra siempre que no sean propiedad de vecinos; mientras que las embarcaciones que traen anchoas y pescado de Levante deben dar una jarra o un tonel, según sea su forma de cargar.

El ancoraje satisfecho en Cádiz eximía de nuevo pago en Sevilla. Y el abonado en este puerto permitía cargar en diversos puntos del río sin sobrepasar Sanlúcar; pero no descargar pasadas Las Horcadas. Por último, las barcas sin góndola y los navíos que cruzaban hasta Coria no estaban obligados a pagar albalá.

110 J. M. Calderón Ortega, El Almirantazgo..., Apéndice no 29.

${ }^{111}$ B(iblioteca) N(acional), Mss 716, "Privilegios y Ordenanzas de Sevilla", fols. 94 vo -95 ro. 
No existen nuevos datos hasta las informaciones de 1456 y $1483^{112}$. La primera incorpora los derechos de exportación, en concreto los pagados por el cahíz de trigo y por el de semillas (garbanzos y similares): 1 franco de oro o 71 maravedís (dobla corriente). Según los siete testigos interrogados se trataba de una práctica "inmemorial". La segunda expone el pago del anclaje, tasado en dos doblas de oro para las carracas, naos y "otros navíos" que viniesen de Sevilla (sic), Sanlúcar, Cádiz y Puerto de Santa María. También revela la liquidación del despacho, cuyos derechos podían igualarse entre los lugartenientes y los patrones o maestres de las naves, para no dar lugar al tercio de carga del almirante, o repartirse entre los cargadores a razón de una dobla por cada cinco toneladas. Entre ambas informaciones se produjo la autorización al almirante para construir un muelle en el Guadalquivir que tendría la exclusiva de carga y descarga, con sus derechos, aunque la iniciativa no prosperó ${ }^{113}$.

\subsection{LA LENTA Y TOTAL TRANSFORMACIÓN}

A fines del siglo XV y comienzos del XVI un sonado pleito enfrentó al almirante y a la ciudad de Sevilla sobre el pago de derechos y su justificación ${ }^{114}$. El arranque del mismo puede situarse en el 6 de febrero de 1497, fecha de la carta de poder del concejo a su procurador, aunque su origen remoto se encuentra en la pesquisa encargada por el concejo municipal el 24 de noviembre de 1483, coetánea por tanto con la segunda de las informaciones arriba señaladas. Los autos judiciales comenzaron en los primeros meses de 1500, con los alegatos de las partes y sus correspondientes interrogatorios, y se prolongaron durante bastantes años. El desarrollo del proceso fue incorporando documentación varia. En unos casos, previa al mismo como los privilegios de los almirantes o las quejas contra su oficio de los maestres y mercaderes gallegos de 28 de marzo de 1491. En otros, coetánea de las actuaciones, como las reales cédulas de 1514 a 1518 regulando el enfrentamiento entre almojarifes y oficiales de la Casa de Contratación por los derechos de las mercancías cargadas y recibidas de Indias. Aunque no consta resolución, parece fuera de toda duda que sus diligencias están en la base de los aranceles de 1506 y $1512^{115}$.

La principal reclamación del concejo era que se trataba de nuevas imposiciones, sin respaldo legal. En su opinión, la razón de las mismas era la transformación del oficio de lugarteniente. Este había dejado de ser el de un asalariado, al que "si alguna cosa le daban era poca cosa"; para convertirse en el de un arrendatario, que pagaba por él "3.000 doblas al año". Lo sustancial del cambio se sitúa en la época de Fernando Díaz de Rivandeneyra (1470-78), quien "comenzó a llevar nuevos derechos". Labor que fue acrecentada por Ruy González de Portillo (1478-80), quien "hizo una nómina de su propia cabeza y autoridad"; y por Jorge de Tordesillas (1480-86). No pudiendo mostrar ordenanzas que regulasen los nuevos derechos, los representantes del almi-

${ }^{112}$ BN, Manuscritos, $\mathrm{n}^{\circ} 17789$ Diferentes noticias... Borrador $\mathrm{n}^{\circ} 18$ : Información de $1456 \mathrm{y} \mathrm{n}^{\mathrm{o}} 26$ : Información de 1483.

113 P. Rufo Ysern: Documentación andaluza ..., no 19 (15-II-1475).

${ }^{114}$ Está recogido en el citado legajo AGI, Justicia, leg. 1143 A y en su continuación en 1143 B.

115 AGS, Cámara de Castilla (Diversos), leg. 6, fols. 25-27: aranceles de 1506 y 1512; AGI, Patronato Real, leg. 295, n 123: arancel de 1512. 
rantazgo se limitaban a invocar la costumbre. Además, se valían de la coacción, pues no tenían superior en la ciudad y manejaban a su antojo la jurisdicción, nombrando a sus oficiales y convirtiéndose en jueces de apelación. El resultado era una creciente presión fiscal, evaluada "en un cuento" al año y que "crece día a día", de tal manera que "si no se pone remedio se llevará más que en el almojarifazgo mayor".

El análisis de los interrogatorios y otras pruebas permiten conocer el catálogo de situaciones a regular y la satisfacción obtenida por las partes. Sus datos pueden resumirse en dos grandes rúbricas: mercancías y embarcaciones

En el capítulo de productos, los cereales ocupan un destacado papel en la controversia. Los antagonistas concordaron que se trataba de bienes gravados desde antiguo debido a su carácter de "vedados", hasta el punto que la pesquisa realizada por la ciudad en 1483 afirma que 25 años antes eran los únicos, en unión de la jarcia, que pagaban derechos. En el interrogatorio que sigue a la pesquisa, el concejo afirma que tales derechos eran de "algunos maravedís". En el desarrollo del pleito, el concejo se quejó que se llevasen 40 maravedís por el cahiz enviado a Guipúzcoa o Vizcaya y "lo que quieren" por el bizcocho cargado. La respuesta del almirante fue que los envíos dentro del reino se gravaban con 40 maravedís por cahiz, que tal cantidad se incrementaba hasta los 71 para las exportaciones fuera del mismo y que el bizcocho pagaba 2,5 maravedís por quintal. En un interrogatorio presentado poco después rebaja la segunda cantidad a 35 maravedís, precisa que el bizcocho era para suministro de las naos e incorpora los 2 maravedís por arroba de harina pagados por quienes traen mantenimientos a la ciudad, en alusión al papel de intercambiador de productos de la alhóndiga del pan. Los gravámenes defendidos por el almirantazgo se ajustan a lo que sabemos de la práctica anterior y a lo recogido en los aranceles posteriores. Tales derechos se acumulaban a los abonados por los albalaes de licencia, como señala la queja de los patrones y mercaderes gallegos, que se querellaron al rey de que les llevaban un real por el del bizcocho y que este producto les era tasado. La respuesta del almirante fue que sólo debían pagar 6 maravedís y que las posibles restricciones eran imputables a los diputados del rey.

En el epígrafe de hierro, grana y lana encontramos menores precisiones. El interrogatorio de la ciudad señala el cobro de 35 maravedís por quintal de hierro o herraje llevado a Jerez, Sanlúcar, El Condado y a los cargaderos intermedios de Lebrija (seguramente Tarfía) y Nueve Suertes. Al mismo tiempo, denuncia que de las granas, cera, lana, peletería y pastel "llevan cuanto quieren". En el primer caso, la respuesta del almirante se limita a admitir el cobro, justificándolo como derecho "antiguo e inmemorial", aunque señala que desde algún tiempo no se lleva nada. En el segundo, precisa que se cobra 10 maravedís por quintal de grana y 6 por saca de lana, negando que se percibiesen derechos sobre peletería, brocados, sedas, paños y lienzos.

La pesca también formó parte del litigio, aunque los temas tratados no abarcan todos los del arancel de 1506. La ciudad protestó contra el cobro de 2 o 3 millares por barco de sardina y 1 millar "o lo que quieren" por el de ostras o almejas. En este último caso, añadió que lo justificaban diciendo "que es para su plato". El almirante respondió que era costumbre inmemorial, en razón de ciertas libertades que sus antecesores habían concedido, llevar 1.100 sardinas a los barcos del arzobispado y el doble a los de fuera del mismo. Y que se percibían 1.100 almejas y 150 ostras por 
embarcación, aunque en un interrogatorio posterior aumenta el número de almejas a 1.200 y añade una docena por barco de sábalos "retrechados". Por su parte, los maestres gallegos, reclamaron contra el gravamen de una dobla por navío, derecho que antes no pagaban. En este caso, la respuesta fue que el tributo era un cesto de sardina o los maravedís que se igualaran.

La información sobre esclavos resulta llamativa por referirse en parte a importaciones. Tanto la ciudad como el almirante admiten el cobro de una dobla por canario traído de las islas, aunque discrepan acerca de la antigüedad de la práctica. Los testigos del almirantazgo hablan de 25, 30 y 35 años, mientras los del concejo no van más allá de los 15 años. Uno de estos afirma que Diego de Herrera, señor de Canarias, sólo pagaba un florín por dichas importaciones. Tales cantidades se recaudaban a pesar de haber satisfecho el quinto real; es más, se veían como un nuevo quinto. El otro supuesto era la exportación de moros, por los que también se recibía una dobla.

El diferendo sobre la moneda nacía de la distinta interpretación de su carácter de producto vedado. La ciudad protestaba de la aplicación exhaustiva de este término, pues afirmaba que se tomaba por descaminado el dinero que circulaba hacia Sanlúcar, Jerez, El Puerto, Cádiz y otros puertos aunque sirviese para la compra de mantenimientos, para hacer tratos comerciales o simplemente para las casas de los portadores. El almirantazgo justificaba el cobro del 5 al millar como fianza de que no se sacaría del reino. Sus testigos confirman dicha práctica desde hacía 30, 35 y 40 años, mientras que los de Sevilla concuerdan en que todo metal amonedado que circulase sin licencia era decomisado por las guardas de Coria, a pesar del juramento de sus dueños sobre su recto uso.

Otro capítulo del pleito concierne a los derechos sobre jarcia y pólvora. Ya hemos visto que la justificación para gravar tales productos era su condición de defendidos, pero la misma debía compatibilizarse con el suministro de las embarcaciones. Por esta última razón, el concejo se quejó de los 35 y 40 maravedís pagados por quintal de jarcia y cáñamo en pelo; a lo que el almirante respondió que llevaba 35 maravedís cuando circulaba "como mercancía" pero tal cantidad descendía a 10 maravedís cuando era "para las carracas y carabelas". En cuanto a la pólvora, la única referencia corresponde al almirantazgo, que reconoció recibir 35 maravedís por quintal.

El resto de mercancías se consideraban exentas, aunque el almirante encontró medios para beneficiarse de ellas. El primero y más común la expedición de licencias. Estas arrancan de los orígenes del sistema, cuando los productos vedados eran los únicos sometidos a gravamen y el resto debía contar con albalá. Su precio era, y en esto están de acuerdo ambas partes, de 6 maravedís. A esta cantidad vino a sumarse luego la abonada en Coria por el registro.

No escaparon de este afán recaudatorio las mercancías enviadas a Berbería, aunque se tratase de productos permitidos. En este caso, la tasa era de 2,5 maravedís al millar o la iguala. Según los testigos del almirante, esta práctica estaba refrendada por una tradición de 25-30 años. Uno de ellos adujo, además, su propia experiencia, afirmando haber realizados envíos de paños y aceites por los que pagó 500 y 600 maravedís.

Otra vía para aumentar la recaudación fue gravar los envases. Según la Ciudad, el régimen primitivo en la carga de toneles, pipas y jarras eran los 6 maravedís del alba- 
lá, sumaran muchos o pocos. Después, el almirantazgo llevó 14 maravedís por tonel (o 15 en el caso de navíos), de los que se descontaba lo necesario para el arrumaje, el trabajo del arrumador y los clavos y madera para el combés. También comenzó a percibir 5 maravedís por las botijas y jarras. El almirante precisó que por tonel cobraba 14 maravedís (o un real si el navío se encontraba en un puerto fuera del río) y la mitad por pipa o bota. Por jarra percibía 3 blancas cuando estaban empegadas y 2 maravedís y $1 / 2$ blanca cuando se habían de llenar, aunque en este caso se añadían 1 maravedí por materiales (corcho y yeso) y otro por el trabajo del enyesador. En otro lugar del pleito, afirma que las jarras pagaban 3 maravedís y 4 coronados. El concejo arreció en sus críticas, señalando que en los 14 maravedís había dejado de entrar el arrumaje y el gasto del enyesador se cobraba aunque las jarras fueran vacías o selladas por sus dueños. Esto último fue negado por la otra parte, que señaló además la importancia del enyesador oficial. La misión de este era evitar fraudes, pues se hacían jarras de dos suelos. En el de arriba iba aceite o vino y en el de otro armas, jaeces, saetas, hierros de lanzas, harina, oro, plata, moneda y otras cosas vedadas.

Otro medio de allegar recursos era la botifuera de Coria, que reunía la inspección de navíos y la venta de mantenimientos. La pesquisa presentada por la Ciudad sostuvo que no existía respaldo legal para llevar derechos y que hasta 30 años antes sólo se pagaba de 4 o 5 cosas "por costumbre o tolerancia, no por ley". Indica, como ejemplo, que por cada tonel de aceite o por cada seis macetas de azogue se abonaba 1 maravedí. Luego, los arrendadores, apoyados en la fuerza que les daba poder detener a los navíos, pidieron derechos de cualquier cosa, hasta el punto que muchas veces percibían más dineros "que en la aduana de Sevilla". La respuesta del almirante fue que sólo se llevaban dos maravedís de registro; que la única fuerza que se hacía era tomar por descaminadas las mercancías sin licencia; y que la taberna era de libre servicio para quienes iban por el río, aunque llegaran a media noche. Los testigos del almirantazgo depusieron conocer la práctica de 30-40 años a esta parte, aunque ninguno de ellos -como indica la anotación de los jueces- llevó el plazo hasta los 50. Uno de los testigos del concejo señaló el comienzo de esta capacidad inspectora en la época de la armada contra Aragón (1430), cuando Diego Vadillo, alcaide de las atarazanas, renunció en favor del almirante la posesión de la barqueta.

En el capítulo de embarcaciones, los derechos a pagar correspondían a tres conceptos: despacho, anclaje y lastre.

El primero era el único que tenía cierto respaldo documental, ya que era una derivación del privilegio de poder cargar un tercio de la embarcación al precio de flete. Tal transformación merecía, sin embargo, una valoración muy diferente de las partes. El almirante la consideraba beneficiosa, pues no retrasaba la partida de los navíos a la espera de que él decidiera hacer efectiva su prerrogativa. La ciudad, por el contrario, estimaba que se trataba de una medida de presión, pues podía aplicarse de forma intermitente y se usaba para obtener mayores derechos bajo amenaza de impedir la marcha. Las igualas eran, por tanto, la forma habitual del impuesto. Según el concejo, fluctuaban entre 10 y 100 doblas; mientras que el almirante las rebajaba sensiblemente, atendiendo a dos escalas. En la primera, el precio ordinario era de 60 maravedís por tonelada, luego rebajado a 50, aunque los arrendadores "hacían sueltas" hasta los 25 o 30, atendiendo a la calidad de la cargazón, los destinos y el origen de los navíos. 
La segunda escala es más precisa y ofrece un panorama del tráfico portuario hispalense. Sus precios eran los siguientes: 4-5 doblas para Madera, Azores, Gran Canaria, Portugal y Valencia; 7-8 doblas para Flandes, Inglaterra, Bretaña y Londres; y 9-10 doblas para Génova, Quíos, Alejandría y otras partes de Levante. Estos precios podían incrementarse atendiendo al tamaño de los navíos. Los testigos del almirantazgo aseguran que este régimen llevaba en vigor al menos 35 años, mientras que los del concejo lo reducen a 15 o 20 . Ambas partes concuerdan en que en caso de que los maestres no pagasen el despacho (en algún caso el despacho y el anclaje), los cargadores debían abonar 1 dobla por cada 5 toneladas.

Como en otros derechos, la polémica sobre el anclaje comienza por la reclamación de la Ciudad. El interrogatorio que presentó en 1500 lo evalúa en 2 doblas y, a veces, en 500 maravedís. La respuesta del almirantazgo reconoce que las embarcaciones de más de 100 toneles pagaban 2 doblas y las menores en proporción, aunque señala que se producían "sueltas", que podían llegar a la totalidad atendiendo a lo pagado por otros conceptos del despacho. Pero en el interrogatorio presentado con posterioridad indica las siguientes cantidades: 2 doblas para las superiores a 200 toneles; 1,5 doblas por las comprendidas entre 100 y 150 toneles; 1 dobla por las de 50-60 toneles; 1 florín por las de 40 toneles; y medio florín por las de 25-30 toneles. Los testigos del almirante atribuyen a la práctica una antigüedad de 35-40 años, mientras que los del concejo la reducen a 25 . Uno de estos ofrece una interesante precisión de carácter técnico y sobre la naturaleza evolutiva del gravamen. Señala que la dobla se pagaba por aquellos navíos que sobrepasaban los 50 toneles y tenían cabestrante y gavias; quedando exentas las embarcaciones descubiertas, tradición que había cambiado recientemente.

Según el concejo municipal, el derecho de lastre gravaba las embarcaciones con un florín de oro o 300 maravedís; y según los maestres gallegos con dos florines por las embarcaciones con gavia y un florín por las que carecían de ella. La respuesta del almirantazgo lo cifra, en ambos casos, en 1 dobla para las embarcaciones de más de 100 toneles y "al respecto" para las inferiores. Pero en un interrogatorio posterior modera la cantidad y la cifra en 1 dobla o florín por las de 200-300 toneles y "dende abajo". Como siempre, los testigos difieren acerca de la antigüedad de la medida. Si los del almirante la elevan a 35-40 años, los de la Ciudad la rebajan a 15 años, en tiempos de Rivandeneyra. Uno de éstos lo retrotrae hasta la época de Alonso de Valladolid, aunque dice que entonces era "por mano de gracia". Los representantes de Sevilla añaden que les hacen pagar en la ciudad aunque lo hayan hecho en Sanlúcar y no obstante que quede allá el navío y no tome lastre. Añaden que les llevan 15-20 reales y más, cuando antiguamente se limitaba a alguna "cortesía"

\subsection{LOS ARANCELES CLÁSICOS}

Las cargas de los aranceles de 1506 y 1512 pueden agruparse en varias rúbricas: navíos, recipientes, jarcia y mercancías, según el siguiente cuadro. 
Derechos de almirantazgo. Años 1506 y 1512

AGS, Cámara de Castilla (Diversos), leg. 6, fols. 25-27 (aranceles de 1506 y 1512); AGI, Patronato Real, leg. 295, $\mathrm{n}^{\circ} 123$ (arancel de 1512)

\begin{tabular}{|c|c|c|}
\hline & 1506 & 1512 \\
\hline \multicolumn{3}{|l|}{ CEREALES } \\
\hline Trigo & $\begin{array}{l}71 \mathrm{mrs} . / \text { cahíz para fuera del Reino } \\
40 \mathrm{mrs} \text {./cahíz para Canarias, Vizcaya y Galicia } \\
24 \mathrm{mrs} . / \text { cahíz para el Condado y su comarca }\end{array}$ & $\begin{array}{l}\text { Ídem } \\
\text { Ídem } \\
34 \mathrm{mrs} \text {. }\end{array}$ \\
\hline Bizcocho & $21 / 2 \mathrm{mrs} . /$ quintal & $\begin{array}{l}\text { Ídem (pero } 11 / 2 \mathrm{mrs} . / \text { quintal para } \\
\text { servicio de la nave) }\end{array}$ \\
\hline Harina & $1 \mathrm{blanca} /$ arroba & Ídem \\
\hline Cebada & Mitad de los derechos del trigo & Ídem \\
\hline HIERRO & $5 \mathrm{mrs} . /$ quintal & $\begin{array}{l}5 \mathrm{mrs} . / \text { qtal. para fuera del Reino } \\
3 \mathrm{mrs} . / \text { qtal. para el Reino }\end{array}$ \\
\hline GRANA & $15 \mathrm{mrs} . /$ frangote o valeta & $10 \mathrm{mrs} . /$ frangote o valeta \\
\hline LANA & $6 \mathrm{mrs} . / \mathrm{saca}$ & Ídem \\
\hline \multicolumn{3}{|l|}{ PESCADO } \\
\hline Sardina & $\begin{array}{l}1 \text { millar/barco, del Arzobispado } \\
2 \text { millares/barco, de fuera } \\
1 \text { cesto(=1000)/barco, de la arencada de Galicia }\end{array}$ & $\begin{array}{l}\text { 1200/bco., del Arzobispado o Portugal } \\
\text { 1200/bco. de Galicia (aunque sea } \\
\text { navío) }\end{array}$ \\
\hline Ostras & $\begin{array}{l}\text { 100/barco, del Arzobispado } \\
\text { 200/barco, de fuera del Arzobispado }\end{array}$ & $\begin{array}{l}\text { 50/barca, del Arzobispado } \\
\text { 100/barca, de fuera del Arzobispado }\end{array}$ \\
\hline Almejas & $1000 /$ barco & $50 /$ barca \\
\hline $\begin{array}{l}\text { Sábalos } \\
\text { (Azamor) }\end{array}$ & 1000/barco & ----- \\
\hline Atunes & $\begin{array}{l}\text { tocinos } 1 \text { de } 12 \text { / barco (y no más) } \\
\text { mojama } 1 \text { serón/barco } \\
\text { embarrilado } 1 \text { barril/barco }\end{array}$ & ----- \\
\hline $\begin{array}{l}\text { Corvinas } \\
\text { saladas }\end{array}$ & $\begin{array}{l}2 \text { corvinas / barco, extranjero } \\
1 \text { corvina / barco, de la tierra }\end{array}$ & ----- \\
\hline Anchoas & 1 barril / [embarcación] & ---- \\
\hline JABÓN & 3 blancas / quintal o sera & $11 / 2 \mathrm{mrs}$./quintal o sera \\
\hline \multicolumn{3}{|c|}{ SEMILLAS } \\
\hline Habas & Como el trigo & ----- \\
\hline Garbanzos & Como el trigo & $\begin{array}{ll}---- \\
--\end{array}$ \\
\hline Anís & Como el trigo & ----- \\
\hline $\begin{array}{l}\text { CUERO } \\
\text { VACUNO } \\
\text { (Curtido o al pelo) } \\
\end{array}$ & 2 mrs. / cuero & $\begin{array}{ll}---- \\
---\end{array}$ \\
\hline AZAFRÁN & $1 \mathrm{mrs}$. / libra & ----- \\
\hline SEDA & $1 \mathrm{mrs} . /$ libra & ----- \\
\hline ESCLAVOS & $\begin{array}{l}1 \text { dobla / esclavo, para fuera del Reino } \\
10 \text { mrs. / esclavo para Sanlúcar, Cádiz o al Puerto } \\
\text { (que sea servicio) }\end{array}$ & ---- \\
\hline PÓLVORA & 35 mrs. / quintal & ----- \\
\hline PLOMO & 5 mrs. / quintal & ----- \\
\hline ACEITUNA & $1 \mathrm{mrs}$. / fanega & $\begin{array}{ll}---- \\
\end{array}$ \\
\hline MONEDA & 5 mrs. / millar & - ---- \\
\hline $\begin{array}{l}\text { OTRAS } \\
\text { MERCANCÍAS }\end{array}$ & 6 mrs. / albalá & 4 mrs. / albalá \\
\hline
\end{tabular}


En el primer epígrafe la principal diferencia entre ambos es que en el de 1506 los navíos locales estaban exentos de despacho, lastre y anclaje, pagando sólo 6 maravedís por el albalá de licencia; mientras que en el de 1512 sólo las embarcaciones menores estaban libres de los mismos, pagando 4 maravedís por el albalá. Las cantidades adeudadas por dichos conceptos presentan una sensible reducción en la segunda fecha, que no se debe a la diferencia antedicha, pues es común a toda la tabla del arancel. El despacho significaba 31 maravedís por tonelada en el primer arancel frente a los 20 del segundo, que además señala un tope de 3.000. El anclaje pasa de dos doblas de oro a 450 maravedís, para navíos de 100 o más toneladas, con disminución proporcional en el resto. En este ramo y sólo en el arancel de 1506, las embarcaciones que traían sardina gozaban de un trato especial, pagando 85 maravedís en el caso del carabelón y 150 en el de la carabela. Y el lastre varía de una dobla a 5 reales de plata, siempre para embarcaciones iguales o superiores a 100 toneladas. Además, en 1506 se incluye el pago en Cádiz de 4 doblas por navío cargado a Berbería, lo que no figura en 1512.

En lo relativo a recipientes y jarcias también se aprecia una sensible disminución entre ambos aranceles. Los derechos por tonel pasan de 14 a 8 maravedís, además de limitarse a los envases llenos; y de 4 maravedís y 4 cornados a $21 / 2$ maravedís para las jarras, aunque en este último caso se percibe un maravedí más por el corcho y el yeso empleados en sellar y arrumar la carga. Por su parte, el quintal de cáñamo se reduce de 35 a 25 maravedís, el de estopa de 10 a 8 y el de sebo de 10 a nada.

Las mercancías gravadas recortan su número entre ambas fechas y sufren también un proceso de aligeramiento, aunque más suave en este caso.

El arancel del Almirantazgo de Granada de $1512^{116}$ es una versión del de Castilla del mismo año, aunque con reducción de capítulos y con cierta personalidad comercial. En lo tocante al navío, el despacho baja a 15 maravedís por tonelada, el anclaje se mantiene igual y no figura el lastre. Además, la licencia para los navíos menores desciende a 3 maravedís por albalá. En cuanto a los recipientes, las tarifas bajan a 6 maravedís por tonel y 2 por jarra. Los materiales pagan los mismos derechos, lo que también sucede con buena parte de las mercancías (bizcocho, harina, hierro y seda). El trigo para fuera del reino -en este caso, de Granada- desciende a 60 maravedís por cahíz y el redistribuido dentro de él baja a 36. La grana disminuye hasta los 6 maravedís por frangote o valeta; mientras que la lana lo hace a 4 por saca. El único pescado reseñado es la sardina, traída de Portugal y Galicia, que bajaba a 600 unidades, aunque se tratase de navíos. El pago por pasas e higos almendrados es exclusivo de este arancel, en el que queda fijado en 3 maravedís por quintal.

Los aranceles que venimos comentando eran de aplicación en el Arzobispado de Sevilla, por más que el título que daba derecho a ellos fuese el de Almirante de Castilla. Esto plantea el problema de la situación en el reino de Granada con anterioridad a 1512. La documentación que manejamos no da respuesta clara a este dilema, aunque apunta a un "tira y afloja" vinculado a la duración de las franquezas otorgadas a los repobladores ${ }^{117}$. En agosto de 1503 , el rey confirmó -a pesar de la oposición de los

${ }^{116}$ ADA, 78.18 (1): Burgos, 6 de marzo de 1512.

117 En la sobrecarta del título de almirante de Granada se constata que las partes contrarias a la misma habían argumentado que las villas de ese reino eran francas por cartas y privilegios ... y que con 
escribanos del número de Málaga- una real cédula que ordenaba guardar al almirante "de Castilla y Granada" el ejercicio de los casos y cosas de su oficio ante el escribano que él nombrase, "según y cómo lo usaba y ponía en la ciudad de Sevilla"118. Lo que sí sabemos fehacientemente es que la promulgación del arancel no significó el final del conflicto ${ }^{119}$.

Como sucedía en otros apartados, las mercancías cargadas en servicio del rey estaban exentas de derechos ${ }^{120}$.

La percepción de tales gravámenes chocaba con otras jurisdicciones. En primer lugar las señoriales, especialmente las del marqués de Cádiz y el duque de Medina Sidonia, quienes pretendían eludir el pago de dichos gravámenes en sus dominios ${ }^{121}$. También con las concejiles, caso de Sevilla ${ }^{122}$. Tampoco faltan roces con la naciente

sólo este título se han poblado". Vid. J. M. CALDERón, El almirantazgo..., Apéndice nº 42: Burgos, 12 de agosto 1512.

Sobre esta cuestión vid. M. A. LADERo QueSADA, "La repoblación del reino de Granada anterior al año 1500”, Hispania XXVIII (1968), pp. 489-563; y XXIX (1969), pp. 355-424.

118 ADA, 78.4: El rey ordena guardar la primera cédula, a pesar de la elevación por parte del corregidor de la ciudad de la oposición de los escribanos "por ir contra sus privilegios" (Valladolid, $27 \mathrm{~d}$ agosto de 1503). Es por tanto anterior a la confirmación de 5 de Mayo de 1505, recogida por C. FERNÁNDEZ Duro, Armada española desde la unión de los reinos de Castilla y Aragón, Madrid, 1972. Apéndices, p. 396 y tenida como la primera concesión del almirantazgo de Granada.

119 ADA, 78.32: Real Cédula al corregidor de Málaga, recordando la obligación de pagar al Almirante los derechos de anclaje y tonelada (5-II-1515); $\mathrm{n}^{\circ}$ 161: Ídem, haciendo extensivos dichos derechos a los mercaderes de San Sebastián y Motrico, a pesar de sus franquezas (14-II-1515); n 164: Concordia entre el Capitán General de Granada y los mensajeros de Málaga sobre los derechos del almirantazgo (1-XII-1516); etc.

BN, Manuscritos, $\mathrm{n}^{\circ} 17789$ Diferentes noticias... Borrador... no 38: Real Cédula (22-III-1518), que inserta cuatro anteriores, entre las que se cuenta una a las justicias de Andalucía y Málaga para que se acuda al Almirante con los medios quintos de las presas de mar y tierra y cabalgadas de moros; $\mathrm{y} \mathrm{n}^{\mathrm{o}}$ 41: Real Cédula (20-X-1525), declarando que las mercedes de los quintos de cabalgada en las costas y mar del reino de Granada no debían entenderse en perjuicio del derecho del Almirante al medio quinto.

Otros detalles sobre estos enfrentamientos en M ${ }^{\mathrm{a}}$ T. LóPez Beltrán, El puerto de Málaga..., pp. 195 y ss.

${ }^{120}$ BN, Manuscritos, $\mathrm{n}^{\circ} 17789$ Diferentes noticias... Borrador...n $\mathrm{n}^{\circ}$ 33: Para que el almirante no lleve derechos de almirantazgo, anclaje, lastre, despacho o marco a los maestres que han de conducir el trigo, harina, cebada y vino que el rey mandó comprar a Juan López de Recalde, contador de la Casa de Contratación, para el ejército, "porque lo que han de llevar y traer es propio de S. M". (16-III-1512).

${ }^{121}$ AGS, Registro General del Sello, 25-X-1483, fols. 22 y 23: Órdenes a D. Rodrigo Ponce y a D. Enrique de Guzmán para que paguen al almirante los derechos correspondientes a la carga de pan.

ADA, 78.36: Relación de documentos entregados por el Almirante a su lugarteniente. 12: Para que el Asistente de Sevilla haga pagar a la duquesa de Medina y a otras personas tales derechos (s.1., 30 de octubre de 1512).

${ }^{122} \mathrm{M}^{\mathrm{a}}$ J. SANZ y M $\mathrm{M}^{\mathrm{a}}$ I. Simó, Catálogo de documentos ... $\mathrm{n}^{\mathrm{o}}$ 1414: el lugarteniente del almirante se querella ante el concejo de los vecinos que sacan toneles y pipas de aceite y otras mercancías sin pagar los derechos de almirantazgo (2-III-11453); $\mathrm{n}^{\circ}$ 1503: los armadores y pescadores de Sevilla se querellan al concejo de que el almirante les obliga a pagar tributos, en contra de sus privilegios (1-XI-1453); $\mathrm{n}^{\circ}$ 1597: los pescadores de Sevilla se quejan porque el lugarteniente de almirante les hace pagar grandes cuantías por la sardina que traen del mar (6-XI-1454); y n² 2019: Los barqueros de Córdoba que viene a Sevilla piden que el teniente de almirante no les cobre impuesto nuevo por los barcos que suben vacíos (15-X-1470); Archivo Municipal de Sevilla, Sección 1 ${ }^{\mathrm{a}}$, Carpeta 109, $\mathrm{n}^{\circ}$ 17: Pesquisa de Pedro de Maluenda, juez de suplicaciones de Sevilla, sobre la denuncia de D. Pedro Niño, teniente de almirante, contra Álvaro de Valladolid. Éste estorbó la actuación de Diego de Mesa, alcalde de la mar por el Almi- 
Casa de Contratación. En este terreno, los almirantes se proveyeron de una serie de reales cédulas para que los oficiales de la Casa sólo pudiesen conocer de las cosas que fueran para Indias y para que diesen cuenta de la cargazón y descargazón que viniere de Indias ${ }^{123}$. En este caso, parece que no llegaron a cobrarse tales derechos, aunque el Almirante se vio compensado por ello, primero de forma temporal y luego de forma definitiva ${ }^{124}$.

Sin embargo, la gran pugna en este ámbito se produjo con los arrendadores del almojarifazgo mayor de Sevilla, si bien aquí la cuestión estaba íntimamente ligada con el último aspecto de la función inspectora del almirantazgo: el control de la saca de productos vedados.

\section{LA GUARDA DE LAS “COSAS VEDADAS"}

La política de productos vedados estaba orientada a asegurar la defensa del Reino, tanto en el plano económico como militar. Garantizaba la existencia de productos básicos (alimentos, moneda y metales para amonedar, caballos y armas), al tiempo que dificultaba el abastecimiento de los posibles enemigos. Esta política se enfrentaba, no obstante, con un amplio número de excepciones, legalizadas mediante el sistema de sacas, y con la naturaleza del comercio en la fachada meridional del reino.

Las sacas se utilizaban, en primer lugar, para posibilitar importaciones. Este es el caso de los envíos de plata a Berbería para obtener pan ${ }^{125}$; aunque no todo este comercio estaba autorizado ${ }^{126}$. Por la misma razón se permitía el envío de dinero a Portugal

rante, contra los maestres de 4 naos vascas surtas en el río, en las que había cargado aceite. Por su acción, los maestres se fueron sin dar fianzas sobre los derechos de almirantazgo y sin requerir a los guardas de Coria para que viesen si llevaban cosas vedadas. Además, a petición suya el teniente de Asistente mandó prender al alguacil del almirante. La argumentación de Álvaro de Valladolid era que el Almirante y el dicho alguacil, alcalde y sus oficiales eran todos unos robadores (27-VI-1499).

R. CARANDE y J. CARriazo: Tumbo..., II, 287 (7-I-1484); II, 297 (17-III-1484);II-298 (17-III-1484); II, 299 (1484); II, 333 (3-VII-1484) y II, 369 (22-IX-1484): Pleito sobre jurisdicción y, sobre todo, derechos.

${ }^{123}$ ADA 78. 36: no 14 (13-XII-1511), 23 (25-IX-1512), 26 (16-XII-1512).

${ }_{124}$ BN, Manuscritos, $\mathrm{n}^{\circ} 17789$ Diferentes noticias... Copia de la $3^{a}$ representación: Real Cédula (22-III-1518), mandando pagar al Almirante 400.000 mrs. en la Casa de Contratación (130.000 por equivalencia de los derechos que pretendía tocarle de lo que se cargaba y venía de Indias y 270.000 por regalía, con lo que parece que quedó redimido el derecho de almirantazgo, por los derechos de carga, descarga, marcos y anclaje); Borrador..., $\mathrm{n}^{\circ}$ 37: Real Cédula (25-X-1513), ordenando al Dr. Matienzo, tesorero de la Casa de Contratación, pagar al Almirante 600.000 mrs., que se le dan en equivalencia de lo que hubo de haber de los derechos de las cosas que se carga para Indias, desde la muerte de la reina $\mathrm{D}^{\mathrm{a}}$ Isabel hasta el día de la fecha.

${ }^{125}$ R. CARAnde y J. CARriazo: Tumbo..., III, 108 (16-VII-1486) y III, 320 (7-X-1489): Importaciones desde Casa del Caballero y reino de Fez.

Los vecinos de Lagos se quejaron en las Cortes de 1490 del comercio castellano de plata por pan en Mazagán y Casa del Caballero. Vid. V. Magalhaes Godinho, "Les guerres du blé au Maroc", Anuario de Historia Económica y Social 1 (1968), p. 243.

${ }^{126}$ AGS, Registro General del Sello, 12 de octubre de 1484, fol. 168: Secuestro de bienes para quienes han sacado moneda o metales para la Casa del Caballero. 
a fin de obtener pescado ${ }^{127}$. Las sacas también se empleaban para cumplir compromisos exteriores de la Corona, como los permisos para el envío de mantenimientos $\mathrm{y}$ armas a las plazas portuguesas ${ }^{128}$. A este respecto hay que recordar que el rey de Portugal creó un consorcio con mercaderes portugueses y genoveses para aprovisionar Ceuta desde Castilla, Sicilia y otras regiones ${ }^{129}$. Desde esta perspectiva no puede sorprender que el monarca ordenara devolver Ruy Pérez, criado del rey de Portugal, los 19.800 maravedís que le había cobrado el teniente de almirante por los derechos de 6.400 cahices de trigo vendidos por el duque de Medina Sidonia ${ }^{130}$.

Otra modalidad de la concesión de sacas era la suspensión de normas locales que impedían el libre tránsito de productos, a pesar de que éste estuviese garantizado por leyes de Cortes. Tales autorizaciones se encaminaban a asegurar objetivos regios, como el abastecimiento de zonas deficitarias y necesidades militares ${ }^{131}$. En este capítulo también deben incluirse los envíos de mantenimientos, ganados y otras mercancías entre las coronas de Castilla y Aragón, a tenor de lo dispuesto en las Cortes de Toledo de 1480 y recogido en las Ordenanzas Reales de Castilla ${ }^{132}$. En los mismos estaban taxativamente excluidos la moneda y los metales susceptibles de amonedar. En este capítulo tenía un papel primordial el oro, traído del norte de África y reexportado hacia otras regiones europeas, normalmente de forma fraudulenta ${ }^{133}$. En otras ocasiones se trataba de simples mercedes a particulares, bien productores y detentadores de renta o bien comerciantes ${ }^{134}$. Las sacas, sobre todo las de carácter individual, solían comportar un doble beneficio: posibilidad de exportar un bien habitualmente restringido y hacerlo sin pagar derechos. Esto último, no era norma general y en algún caso se exceptuaba la parte correspondiente al almirante ${ }^{135}$.

En el comercio con tierras de infieles estas autorizaciones podían completarse con seguros, dado su inestable carácter legal. Los seguros podían ser generales, bien a

${ }^{127}$ R. Carande y J. Carriazo, Tumbo..., III, 326 (6-X-1489).

128 . A. De la Torre y L. SuÁrez, Documentos... Portugal..., II, nº 400, 401 y 432: Saca de 300, 200 y 500 cahíces (14-I-1494, 20-I-1494 y 4-X-1494).

AGS, Registro General del Sello, 7 de septiembre de 1489, fol. 5: Armas para la defensa de La Graciosa, ocupada por el rey de Fez.

129 V. Magalhaes Godinho: Les guerres... p. 232.

${ }^{130}$ ADA, 78.2: Para que el Corregidor de Jerez cumpla una provisión anterior que así lo establecía (1502)

131 R. Carande y J. Carriazo, Tumbo..., I, 70, 174, 183, 184 y 323; II, 346: Saca para Palos y para la flota de Portugal.

AGS, Registro General del Sello, 23 julio 1489, fol. 4: Saca para Vera; y 4 de junio de 1492: Saca para Almería, Almuñécar y reino de Granada.

Vid además otras notas.

${ }^{132}$ Cortes de los antiguos reinos de León y Castilla, Tomo IV. Madrid, 1882. P. 185: Ley 111.

${ }^{133}$ Sobre esta cuestión vid. E. Aznar Vallejo, Navegación oceánica...p. 363. Y M. A. LAdERo QueSADA, "Los genoveses y la saca de moneda de oro castellana. 1500-1503", Anuario de Estudios Medievales 17 (1988). Pp. 571-594.

${ }^{134}$ Citamos, a modo de ejemplo, P. Rufo Ysern, Documentación andaluza..., n ${ }^{\circ}$ 275: Saca a favor del protonotario D. Álvaro de Luna (24-VII-1476); y no 886: Ataque de vecinos de Palos contra súbditos del reino de Aragón que llevaban trigo a Valencia, con licencia del rey (21-XI-1477).

${ }_{135}$ P. Rufo Ysern, Documentación andaluza..., no 324: Merced de saca a don Pedro Enríquez, exenta de derechos, a excepción de los que cobra el almirante (23-X-1476). 
favor de los naturales del reino ${ }^{136}$, bien a favor de los portugueses que comerciaban con Berbería, o bien a favor de los moros bajo obediencia lusitana, como en el caso de Azamor ${ }^{137}$. Ello no era impedimento para que existieran otros individuales, bien a favor de los mismos grupos o de otros, como los genoveses ${ }^{138}$. La casuística de los mismos es muy variada: castellanos que desean traer sus bienes desde allende ${ }^{139}$; salvoconducto a portugueses que deben atravesar aguas castellanas para dirigirse a Berbería $^{140}$ o que desean enviar mercancías a tierras de moros ${ }^{141}$; seguro a moros fiadores de castellanos ${ }^{142}$, etc. En algunos de estos seguros se añadía la coletilla "con tal que no sean mercancías vedadas", lo que no dejaba de ser -como hemos dicho- un mero formulismo ${ }^{143}$. A todas estas excepciones hay que sumar el contrabando pues el comercio con Berbería descansaba sobre la exportación de productos vedados ${ }^{144}$. Así queda de manifiesto en la real cédula ordenando la inhibición de los jueces en las denuncias sobre veinte años de contrabando en el Cabo de Aguer ${ }^{145}$. Y lo mismo se puede deducir de las licencias ocasionales de la monarquía que autorizaban lo que habitualmente perseguían; y de la actitud permisiva de los representantes regios. En 1460 , por ejemplo, tanto los almojarifes como el lugarteniente del Almirante se quejaron de una comisión real contra las personas que llevaron mantenimientos y otras cosas a Berbería, por ser "deservicio del rey y gran daño y menoscabo en las dichas cosas y rentas" 146 .

A pesar del carácter laxo de la política de productos vedados, conocemos algunas iniciativas del almirante en este campo, aparte de lo argumentado a la hora de percibir

${ }^{136}$ R. Carande y J.M. Carriazo, Tumbo..., Tomo III, II-178: Con tal que no vayan al reino de Granada ni pasen el Estrecho (28-IX-1482).

137 R. Carande y J.M. Carriazo, Tumbo..., Tomo IV, III-142 (4-I-1487).

${ }^{138}$ AGS, Registro General del Sello, 13 Septiembre 1478: a favor de Pedro de las Calonias, residente en Sevilla y de su nao "Santa María del Aguila" en viaje a Safi; y 6 Diciembre 1484: a favor de Domingo Espíndola, residente en Sevilla, para ir a cualquier puerto de Berbería.

139 AGS, Registro General del Sello, 28 Agosto 1478: a favor de Ruy López de Alcaraz para traer sus bienes desde Ceuta, Tánger y Arcila.

${ }^{140}$ AGS, Registro General del Sello, 24 Noviembre 1478: a favor de Fernando de Lemos y Vasco de Gama de camino a Tánger.

${ }^{141}$ AGS, Registro General del Sello, 5 Abril 1480: a favor de Rodrigo Afonso, caballero de la casa del rey de Portugal.

${ }_{142}$ AGS, Registro General del Sello, 5 Septiembre 1485: Real Cédula para que no se cautive a Hamet Buhedor, fiador de Juan Garrido, vecino de Gibraltar. Este, cautivo de los moros del reino de Fez, se rescató por un moro que está en Puerto Real. Para pagar el precio tiene licencia para pedir limosna por el Reino, en unión de Hamet.

${ }^{143}$ AGS, Registro General del Sello, 9 Diciembre 1486: a favor de Diego de Valera, que conduce esclavos y mercancías a la costa de Berbería.

${ }_{144}$ AGS, Estado (Castilla), leg. 1, 2º $n^{\circ} 75$ : Acusación contra los vecinos de Palos que aprovechaban las pesquerías del Cabo de Aguer para llevar armas y jaeces, obteniendo a cambio oro, esclavos y cera.

${ }^{145}$ AGS, Registro General del Sello, 13 de Mayo 1495: Para que Alonso Franco, vecino de Palos, cobre el salario por realizar tal gestión.

146 I. Montes Romero-CAMACho, "Algunos datos sobre las relaciones de Castilla con el Norte de África: Sevilla y Berbería durante el reinado de Enrique IV (1454-1474)". Estudios de Historia y Arqueología Medievales Vy VI. Cádiz, 1985-86, pp. 247-249. Vid también Mª J. SANz y Ma I. Simó, Catálogo de documentos.... $\mathrm{n}^{\circ} 1862$ y 1863. 
los derechos de registro. En 1505, su lugarteniente en Jerez decomisó 195 espadas guarnecidas, listas para enviar a Berbería, y pidió ayuda a las justicias del Puerto de Santa María para castigar el hecho ${ }^{147}$. Como siempre, los responsables locales se mostraron evasivos, diciendo "que estaban prestos a dar dicha ayuda en cuanto alcanzare la jurisdicción del almirante, pero que en lo demás harían lo que debían en nombre del duque de Medinaceli". La misma oposición encontramos en el concejo hispalense, que en 1429 recibió a Luis Fernández Marmolejo llanamente como lugarteniente, pero no en cuanto guarda de la barquería de las cosas vedadas, pues uno de los regidores protestó por tenerla él ${ }^{148}$. A las citadas iniciativas hay que unir su función inspectora sobre los barcos cargados en Cádiz para Berbería, remunerada con 4 doblas por embarcación en el arancel de 1506; y la pesquisa que ordenó hacer en 1442 contra quienes sacaban pan, ganados y otras muchas cosas por mar para tierra de moros, "en especial para el reino de Granada y Portugal"149.

Lo anterior limitaba la actuación del Almirante al cumplimiento de las citadas sacas y seguros. Esto, sin embargo, le proporcionaba importantes ingresos, como hemos visto al hablar de los arrendamientos. Señalamos allí que las exportaciones a puertos castellanos privilegiados no escapaban a dicha norma. Las únicas diferencias eran que los derechos a pagar eran menores, como muestran los aranceles; y que su revocación era más difícil de conseguir, como testimonia la cláusula del arrendamiento de 1455-57 que obligaba al arrendador a paralizar las licencias para los otros destinos, hasta que el almirante fuese requerido. Los destinos privilegiados se concentraban en las provincias vascongadas, a los que podían unirse otros de la actual Cantabria, Galicia, Canarias o Murcia. Ello se traducía en abundantes licencias de saca. Unas veces se trataba de concesiones a instituciones, caso del concejo de $\mathrm{La}$ Coruña, condado de Vizcaya o provincia de Guipúzcoa ${ }^{150}$; mientras que otras lo son a particulares de algunos puertos de dichas regiones ${ }^{151}$.

El escaso papel del almirantazgo en el control de los productos vedados se veía incrementado por las concesiones reales a ciertos particulares. En primer lugar, la creación de la alcaldía mayor de las sacas y cosas vedadas del arzobispado de Sevilla, de la que tenemos constancia con anterioridad a 1445. En ese año, Juan II la concedió, por destitución de Pedro Vaca, a Gonzalo de Saavedra, quien tres años más tarde recibió confirmación de Enrique IV ${ }^{152}$. En 1478, su hijo Fernando Arias de Saavedra fue restituido en el oficio, al revocarse la concesión hecha a Hurtado de Mendoza ${ }^{153}$. En su ámbito jurisdiccional funcionaron diversas guardas, especializadas en las diversas fronteras y en la saca del pan. Esta última era la que afectaba a las rentas del almiran-

${ }^{147}$ A.D.A 78.8: Transporte en barco de 195 espadas, para cargarlas en una nao surta en la bahía (18VII-1505).

148 BN, Manuscritos, no 17789 Diferentes noticias... Borrador $\mathrm{n}^{\circ} 10$.

149 ADA, 77.38: Garfín, 4 de septiembre de 1442.

${ }^{150}$ Citamos, a modo de ejemplo, P. Rufo YSERn, Documentación andaluza..., n 206: a petición del concejo de La Coruña y del alcaide de su fortaleza (20V-1476) y n ${ }^{\circ} 347$ : a petición del capitán de la provincia de Guipúzcoa e hidalgos de la misma, para dicha provincia y condado de Vizcaya (4-XII-1476)

151 Citamos, a modo de ejemplo, Ídem n ${ }^{\circ}$ 1418: a petición de 2 vecinos de Guetaria (27-VI-1478).

152 P. RUfo YSERn, Documentación andaluza..., $\mathrm{n}^{\circ}$ 1885: para que se guarden las citadas cartas de merced (11-VII-1479).

153 Ibídem 
tazgo, pues la mayoría de las exportaciones se hacían por la mar. Otorgaba al beneficiario las penas de los infractores, lo que se traducía en la práctica en la instauración de guardas y en la concesión de licencias. Muestra de esta colisión de derechos es la reclamación de Arias Cifuentes, lugarteniente de almirante, contra Rodrigo de Ávila, guarda del pan por el comendador Pedro de Cabrera ${ }^{154}$. La contestación del requerido argumentó que "no entiende perturbar la jurisdicción del almirante, quien nunca tuvo cargo de la saca del pan, antes lo han tenido otras muchas personas por mandado del rey". A lo que añade que "si los que sacan el pan incurren en alguna pena criminal, el almirante puede proceder por su oficio" y que "si ha dado alguna licencia es para que sus guardas dejen a los vecinos llevar harina a sus jábegas". La posibilidad de éxito de la reclamación era nula, no tanto por el razonamiento de la parte contraria cuanto por el apoyo regio. Pedro de Cabrera fue recibido en dos cabildos del concejo sevillano y obtuvo sobrecarta real, a pesar del recurso del almirante. La situación no varió sustancialmente en los años siguientes, en los que encontramos nuevos titulares del cargo (Pedro de Pinos, Alfonso de Ávila, Francisco de Bonaguisa, Francisco Dávila) y en los que se confirmaron sus competencias, a saber: «ninguna persona non pueda sacar el dicho pan nin cosa alguna dello, sin que primeramente ayan de leuar e mostrar çedula firmada de vuestro nombre o de quien uestro poder para ello ouiere, cobrando de cada cahiz de pan, trigo, cebada o centeno que se sacare o cargare, seis maravedís para vuestro salario» ${ }^{155}$. De esta concesión se exceptuaban, a solicitud de Sevilla, las semillas y el bizcocho cargado por sus vecinos y el pan y la harina enviado a las jábegas ${ }^{156}$. La única posibilidad de cambio era la inconstante voluntad de los monarcas, como muestra la orden a Gómez de Solís, alcalde de sacas y cosas vedadas del arzobispado de Sevilla, para que no usase su oficio en los puertos bajo la jurisdicción del almirante ${ }^{157}$.

Además de estas mercedes institucionales, los monarcas concedieron otras esporádicas. Una de ellas produjo la pugna entre Pedro de Segovia, portero de cámara y criado del contador mayor Diego Arias de Ávila, a quien el rey había concedido la exclusiva para conceder sacas pan desde Jerez; y Rodrigo Álvarez de la Becerra, arrendador del almirantazgo, a quien el primero solicitó que diese albalaes a quienes él hubiera otorgado licencias, sin llevarles derechos. Lógicamente el teniente se negó y adujo los privilegios del almirante, que en el momento de la concesión al contador (18-VIII-1455) había vuelto al favor real y le había arrendado el oficio ${ }^{158}$.

${ }^{154}$ A.D.A 77.67: Sevilla, 9-16 mayo 1470.

${ }^{155}$ Las instituciones relacionadas con la saca y en particular con la del pan pueden verse en I. Montes Romero-Camacho, "Las instituciones de la saca en la Sevilla del siglo XV. Aproximación al estudio de la organización institucional del comercio exterior de la Corona de Castilla al final de la Edad Media", Historia, Instituciones, Documentos 31(2004), pp. 417-436. La cita recogida puede verse en la p. 434 de la citada obra. Tales derechos pasaron luego al reino de Granada. Vid F. Bejarano Robles, Catálogo de los documentos del reinado de los Reyes Católicos del archivo municipal de Málaga, Madrid, 1961, n 294: traslado de los derechos de la guarda mayor de la saca del pan de Jerez (15-I-1504).

${ }^{156}$ I. Montes Romero-CAmacho, Las instituciones de la saca ...p. 432.

157 J. M. Calderón Ortega, El Almirantazgo..., Apéndice no 49: Valladolid, 9 de septiembre de 1514. Vid además nota $\mathrm{n}^{\mathrm{0}} 111$, en la que se ordena a los nobles andaluces pagar al almirante los derechos de la carga del pan.

${ }^{158}$ ADA, 77.52: Sevilla, 25 de octubre de 1455. 
Aun así, la limitada eficacia de su labor propició iniciativas directas de los monarcas. En 1489 comisionaron al secretario Alfonso de Ávila y al contino Diego de Ataide para investigar la saca de productos vedados (trigo, cebada, bizcocho, oro y plata, moneda, caballos y armas) que desde hacía siete años venía perpetrándose desde Sevilla, Jerez y otras poblaciones del arzobispado ${ }^{159}$. Los envíos se realizaban, por mar y por tierra, hacia tierra de moros y para fuera del reino. Como jueces ejecutores fueron nombrados el licenciado Diego López de Trujillo y el bachiller Antonio Álvarez de Amusco, sin referencia alguna al almirantazgo ni al alcalde mayor de las sacas y cosas vedadas.

Sin embargo y como habíamos anunciado, el gran choque en estas cuestiones se produjo con los representantes del almojarifazgo mayor. Los arrendadores del almirantazgo pretendían generalizar los albalaes de inspección, so pretexto de impedir el comercio de mercancías prohibidas. Los almojarifes, por su parte, se quejaban de dicha política, porque dificultaba el tráfico y servía para cambiar sus gravámenes por otros más ventajosos. Ambas posturas encontraban apoyo en la naturaleza del comercio con Berbería, que representaba un amplio renglón del comercio exterior andaluz y que se sustentaba mayoritariamente en productos vedados.

En el arrendamiento de 1450-55, los almojarifes obtuvieron confirmación de Juan II de la facultad de poner guardas que catasen los navíos, para evitar que la renta se menoscabase por encubiertas de los vecinos de Sevilla, "especialmente de los que por el almirante andan por la mar"160. A pesar de lo cual, en 1455 encontramos a los tenientes de almirante dando licencias para la saca de pan $^{161}$. En 1484, los reyes recordaron a la ciudad de Sevilla la Ley del Cuaderno que prohibía a los tenientes de almirante dar albalaes de guía para las mercancías que salían por la mar y el río, y autorizaba las guardas y barcas del almojarifazgo ${ }^{162}$. Además, se recriminaba al Almirantazgo el uso de su jurisdicción para disuadir a los guardas de actuar para los almojarifes. Sin embargo, al año siguiente el Adelantado de Andalucía, como juez comisario, aceptó la información presentada por el Almirante de que se trataba de un uso antiguo y autorizó los albalaes y los guardas del almirantazgo en la barqueta de Coria ${ }^{163}$ No obstante lo cual, en 1488 y 1505 vuelve a reiterarse la ley del Cuaderno, a petición de los almojarifes ${ }^{164}$.

En 1505 reaparece dicha pugna, con el requerimiento de Pedro Niño, teniente de almirante, para que las justicias de Sevilla cumplan la real cédula de 14 de marzo que

${ }^{159}$ Curiosamente el documento se conserva en los fondos del almirantazgo, ADA, 77.100: Medina del Campo, 9 de marzo de 1489

${ }^{160}$ AGS, Cámara de Castilla (Diversos), leg. 3-2, n ${ }^{\circ} 60$

${ }^{161}$ ADA, 77.53: pugna entre Rodrigo Álvarez de la Becerra y Alvar Núñez Cabeza de Vaca por la tenencia de Jerez y Puerto de Santa María, con referencia expresa a dichas licencias

${ }^{162}$ R. Carande y J. Carriazo, Tumbo..., II, 347 (4-VIII-1484). Según la pesquisa hecha en 1483 por el concejo de Sevilla, el almirante cobraba 30.000 mrs. a los almojarifes por autorizarles a tener barqueta. Vid AGI, Justicia, leg. 1143 A.

${ }_{163}$ A.D.A 77.95: Sevilla, 14 de febrero de 1485).

164 R. Carande y J. Carriazo, Tumbo..., III, 235 (11-VII-1488). También en A.D.A 77.99: Murcia, 11 de julio de 1488 .

AGI, Justicia, leg. 1143 A. 
les ordena no impedir la jurisdicción del Almirante ${ }^{165}$. En virtud de la misma, solicita la liberación del arrendador de los derechos de almirantazgo en la villa de Coria y del sobreguarda del río Guadalquivir, acusados de llevar derechos indebidos a maestres y navegantes. Al año siguiente se escribe un nuevo capítulo en esta guerra -que parece ser el último- al establecer el arancel: en Coria corresponde al almirantazgo 4 maravedís por cada albalá de mercancías y 2 maravedís por los de barcos o navíos al que las requiere y cata allí, pero añadiendo que corresponde a los almojarifes pagar los dos guardas que el Almirante pone en Coria y en el muelle de Sevilla ${ }^{166}$. Esta debió ser la solución: la incorporación de los guardas del almojarifazgo a la organización del Almirantazgo.

En conclusión, el estudio de las rentas del almirantazgo muestra la profunda evolución del oficio durante el siglo XV. El cargo, nacido como un elemento de servicio al Estado, terminó por convertirse en prebenda de la familia Enríquez. Esto subordinó las prestaciones a la monarquía (guerra naval, control de puertos, vigilancia aduanera) a la obtención de ingresos. Tal hecho se veía agravado porque el arriendo de las rentas comportaba el traspaso de la jurisdicción, lo que suponía, además de un menoscabo para la justicia, una medida de presión para los contribuyentes. La evolución de los arrendamientos apunta a un cierto estancamiento, lo que contrasta con el beneficio creciente de los arrendadores, quienes introdujeron nuevos conceptos impositivos. Al carecer estos de soporte legal, impetraron la "práctica inmemorial", a fin de dotarse de una legitimidad basada en la costumbre.

En el primer ámbito, la guerra del mar, la participación personal del almirante terminó por desaparecer, en un proceso simultáneo al de la sustitución de las galeras reales por veleros contratados para la ocasión. La principal repercusión económica de este cambio fue la atención creciente a los quintos pagados por los particulares. En este terreno, los almirantes trabajaron para que su participación pasara del tercio inicial a la mitad y para que se equiparasen presas marítimas y cabalgadas. La importancia de este ingreso explica la competencia con otros poderes señoriales de la Baja Andalucía y Canarias, donde las actividades que lo generaban constituían un medio de vida y uno de los principales recursos de la población. La misma razón sustenta los choques con la monarquía, ya que esta contaba con tales ganancias para alentar las conquistas en Granada, Canarias y Berbería de Poniente.

En el ámbito del control portuario, constatamos el aumento constante de productos y operaciones sometidas a contribución. Tal aumento nacía de la iniciativa de los recaudadores, lo que movió al concejo hispalense a rebelarse contra tamaña arbitrariedad. La confrontación, que terminó en pleito, permite conocer las posiciones de las partes, al tiempo que nos ilustra acerca de los pormenores del tráfico comercial. En el caso de los productos, asistimos al incremento de su número y de la cantidad

165 ADA, 78.7: Sevilla, 22 de agosto de 1505.

166 BN, Manuscritos, $\mathrm{n}^{\circ} 17789$ Diferentes noticias... Borrador... $\mathrm{n}^{\circ}$ 34: Alonso Jofre, teniente de almirante, nombra a Lorenzo Pinelo como alguacil de la Casa de Contratación (7-IV-1512); n ${ }^{\circ}$ 44: El Consejo acordó suspender, a petición del almirante, el nombramiento de Diego Romero (18-VII-1529); $\mathrm{n}^{\mathrm{o}}$ 43: Nombramiento de Pedro de Saravia como alguacil (25-VI-1529). Por no poder servir el oficio se le sustituye por Francisco de Carvajal, vecino de Sevilla, quien toma posesión el 11-IX-1529. 
pagada por ellos. Proceso que se vio acompañado por la creación de nuevas figuras impositivas: registro y botifuera de Coria, preparación de envases... En cuanto a las embarcaciones, la fórmula consistió en separar y ahondar los conceptos tradicionales: despacho, anclaje y lastre. Los aranceles surgidos de la controversia mitigaron la situación al ofrecer un trato más favorable a los vecinos, al tiempo que fijaban y rebajaban los tipos impositivos.

En cuanto a la vigilancia de los productos vedados, la actividad del almirantazgo fue pequeña, debido a las interferencias de la monarquía, a través de las licencias de saca; y la competencia de otras instituciones, caso de las diversas guardas. El almirantazgo trató de compensar la escasez de ingresos generados por este concepto a través de la inspección de las licencias reales y mediante la competencia desleal con los almojarifes. 